This is the submitted version of the article:

Tang P., Arbiol J.. Engineering surface states of hematite based photoanodes for boosting photoelectrochemical water splitting. Nanoscale Horizons, (2019). 4. : 1256 - . 10.1039/c9nh00368a.

Available at: https://dx.doi.org/10.1039/c9nh00368a 


\title{
Engineering Surface States of Hematite Based Photoanodes for Boosting Photoelectrochemical Water Splitting
}

\author{
PengYi Tang ${ }^{1}$, Jordi Arbiol ${ }^{1,2, *}$ \\ ${ }^{1}$ Catalan Institute of Nanoscience and Nanotechnology (ICN2), CSIC and BIST, Campus \\ UAB, Bellaterra, 08193 Barcelona, Catalonia, Spain. \\ 2 ICREA, Pg. Lluís Companys 23, 08010 Barcelona, Catalonia, Spain. \\ e-mail: arbiol@icrea.cat
}

\begin{abstract}
:
Hematite-based photoanodes are promising candidates for photoelectrochemical water splitting. However, the performance of pristine hematite semiconductors is unsatisfactory due to the charge recombination occurring at the different interfaces: back contact, bulk and semiconductor/electrolyte interfaces. Increasing efforts have been focused on enhancing the performance of hematite based photoanodes via nanostructure control, doping, heterojunction construction, and surface modification with a secondary semiconductor or oxygen evolution electrocatalyst. Most of the previous studies attributed the enhanced PEC water splitting performance to the changes on the donor density via doping, the formation of type II heterojunction via a secondary semiconductor coating and the improved water oxidation kinetics via coating oxygen evolution electrocatalysts. Albeit, the role of surface states presented at the semiconductor/electrolyte interfaces of hematite-based photoanodes has been overlooked in the previous investigations, which virtually plays a critical role in determining the photoelectrochemical water oxidation process. In this review, we summarize the recent progress of various techniques employed for the detection of surface sates at hematite photoanodes and highlight the important role of modifying surface sates in the development of high performance hematite based photoanodes for photoelectrochemical water splitting application. The challenges and future tendencies in the study of hematite based photoanodes are also discussed.
\end{abstract}




\section{Introduction}

The increasing global energy demand of modern society drastically conflicts with the finite fossil fuel supply in nature, motivating plenty of research efforts for the development of sustainable and environmental friendly energy sources. [1] Inexhaustible solar energy is among the most promising candidates, and has been utilized widely in photovoltaic approaches. [2] However, the fluctuant and intermittent natures of insolation make such applications unsuitable for the storage and dispatch of solar energy for consumption. [3] Accordingly, conversion of solar energy into the form of chemical bonds is an attractive approach for efficient, economical, and convenient utilization of solar energy. [4-6] Among these strategies, photoelectrochemical (PEC) water splitting devices, using earth abundant semiconductors, have for long been considered to be the 'Holy Grail' of the solar energy conversion revolution. [7-9]

As an earth abundant semiconductor, hematite photoanodes have been intensively investigated as photoanodes for PEC water splitting because of several promising properties, like high abundancy in nature, environmental-friendliness, high photochemically stability, a narrow bandgap (1.9-2.2 eV), and a theoretical maximum solar-to-hydrogen (STH) efficiency of 15.4\%. [10-11] However, its relatively low absorption coefficient, short excited-state lifetime $\left(10^{-6} \mathrm{~s}\right)$, [12-13] poor oxygen evolution reaction kinetics, short hole diffusion length, and poor electrical conductivity lead to multiple electron-hole recombination pathways occurring in the bulk, interfaces, and surfaces, which significantly limits the PEC activity of hematite photoanodes. [11] A rapid charge transport and transfer between the back substrate, the photoactive semiconductor, the electrocatalyst and the electrolyte are necessary for an efficient STH performance. [14] Recently, plenty of researchers have devoted their efforts to the development of various nanostructures, doping, heterojunction construction, and surface modification with a secondary semiconductor or oxygen evolution electrocatalyst for improving the PEC performance of hematite based photoanodes. [11, 15-35] Typically, they attributed the enhanced PEC water splitting performance of hematite composite electrodes to the changes in the donor density via doping, improved charge separation efficiency via constructing type II heterojunctions, and the enhanced water oxidation kinetics via coating oxygen evolution electrocatalyst. [11, 15-35] However, the investigation about the surface states mediated charge transfer at the semiconductorelectrolyte interfaces of hematite based photoanodes has not been properly considered 
by the research community of PEC water splitting, which is critical for understanding the PEC mechanism and further improving its PEC performance.

In this review, we will correct this deficiency and highlight the role of surface states present at the hematite/electrolyte interfaces, which is important for the further development of hematite-based photoanodes for PEC water splitting.[36-37] Specifically, we will review the development of hematite-based photoanodes following this outline: (i) The fundamental concept of photoelectrochemistry and surface states; (ii) Detecting the surface states at hematite via different techniques; (iii) Engineering of surface states at hematite photoanodes.

\section{The Fundamental Concept of Photoelectrochemistry and Surface}

\section{States}

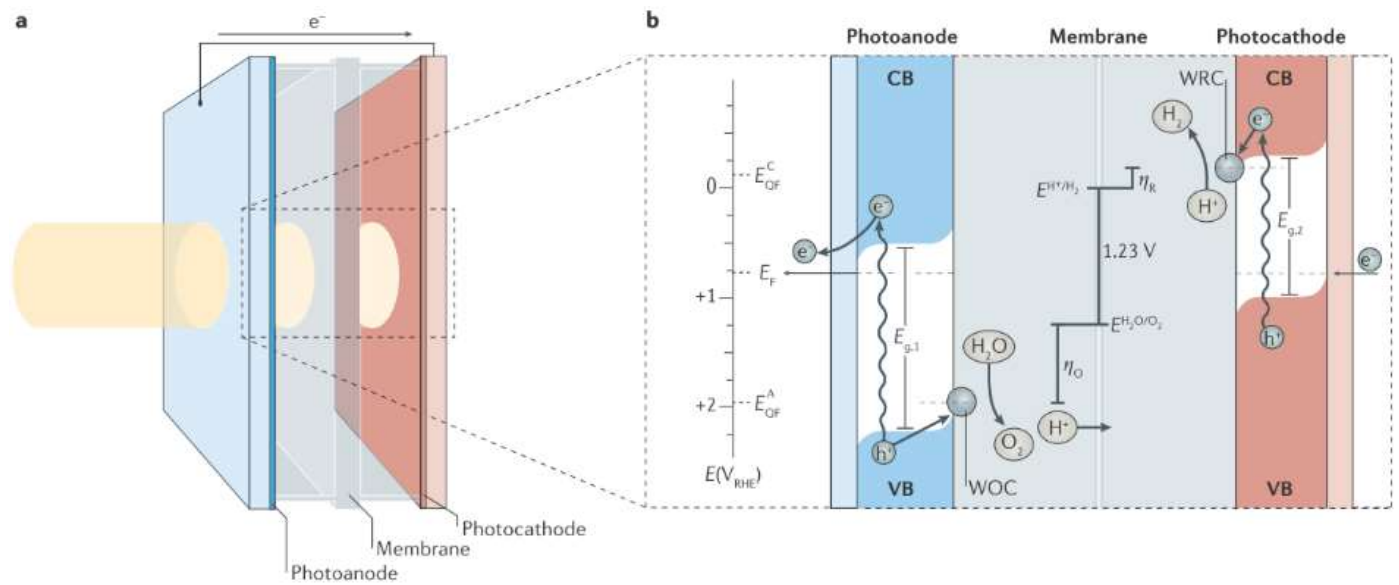

Figure 1. Photoelectrochemical cell basics. (a) Schematic of a 'wired'-type tandem cell for water splitting with incident solar illumination striking the photoanode and transmitting to the photocathode. (b) Working principle of the tandem cell for water splitting using a photoanode with bandgap energy $\mathrm{E}_{\mathrm{g}, 1}$, and a photocathode with $E_{g, 2}$ (where $E_{g, 1}>E_{g, 2}$ ). Briefly, on absorption of a solar photon, an electron $\left(\mathrm{e}^{-}\right)$ from the valence band (VB) is promoted to the conduction band (CB) leaving the corresponding electron hole $\left(\mathrm{h}^{+}\right)$. The electric field in the depletion layer physically separates these charges and, in the photocathode, the electrons in the $\mathrm{CB}$ drift to the semiconductor-liquid junction, increasing the quasiFermi energy of the cathode, $E_{Q F}^{C}$, to drive the reduction of $\mathrm{H}^{+}$to $\mathrm{H}_{2}$ at a water reduction catalysis (WRC) site. Analogously, in the photoanode, electron holes in the VB drift to the semiconductor-liquid junction, increasing the photoanode's quasi-Fermi energy, $E_{Q F}^{A}$, sufficiently to surmount the overpotential for oxidation $\left(\eta_{0}\right)$ and oxidize water to $\mathrm{O}_{2}$ at a water oxidation catalysis (WOC) site. Photogenerated electrons in the $\mathrm{CB}$ of the photoanode travel through the external circuit to recombine with the holes in the $\mathrm{VB}$ of the photocathode. $\mathrm{E}_{\mathrm{F}}$, Fermi energy; $\mathrm{E}\left(\mathrm{V}_{\mathrm{RHE}}\right)$, electronic potential with respect to the reversible hydrogen electrode; $\eta_{\mathrm{R}}$, overpotential for reduction. Reproduced with permission from ref. [10]

The free energy required for the conversion of $1 \mathrm{H}_{2} \mathrm{O}$ molecule to $\mathrm{H}_{2}$ and $1 / 2 \mathrm{O}_{2}$ molecules under standard conditions is $\Delta \mathrm{G}=237.2 \mathrm{~kJ} \mathrm{~mol}^{-1}$. [3] According to the Nernst equation, it corresponds to $\Delta \mathrm{E}^{\circ}=1.23 \mathrm{~V} /$ transferred electron. Theoretically, a semiconductor with a band gap energy $\left(E_{\mathrm{g}}\right)$ larger than $1.23 \mathrm{eV}$ can drive the hydrogen evolution reaction (HER) and oxygen evolution reaction (OER) using electrons/holes 
generated under illumination (Figure 1) if it has a conduction band edge energy $\left(E_{c b}\right)$ and valence band edge energy $\left(\mathrm{E}_{\mathrm{vb}}\right)$ that straddles the electrochemical potentials of $\mathrm{E}^{\circ}$ $\left(\mathrm{H}^{+} / \mathrm{H}_{2}\right)$ and $\mathrm{E}^{\circ}\left(\mathrm{O}_{2} / \mathrm{H}_{2} \mathrm{O}\right)$. To drive these two reactions, photoinduced electrons or holes in the semiconductor bulk must travel to the semiconductor/electrolyte interfaces (SEI), and then react with electrolyte species directly at the semiconductor surface without recombination. The charge-transfer process at SEI results in losses because of the concentration and kinetic overpotentials for driving the HER and the OER. Therefore, the energy required for photoelectrochemical water splitting at a photoelectrode is usually reported as 1.6-2.4 eV/generated electron-hole pair. [38-39]

Whereas, at the surface of a practical semiconductor, the periodic crystal symmetry is broken and thus, produces electronic states within the bandgap, which are named as surface states/mid-gap states. [40] The surface states presented at the surface of semiconductors can either be intrinsic or extrinsic, which relies on the environmental conditions of the semiconductors. In the field of semiconductor photoelectrochemistry, surface states play a vital role on the kinetics of interfacial reactions at illuminated semiconductor electrodes. Recently, the investigation of surface states affecting the kinetics of $\mathrm{Fe}_{2} \mathrm{O}_{3}, \mathrm{BiVO}_{4}, \mathrm{CuWO}_{4}, \mathrm{GaN}, \quad \mathrm{CuFeO}_{2}, \mathrm{Ta}_{3} \mathrm{~N}_{5}, \mathrm{Cu}(\mathrm{In}, \mathrm{Ga})(\mathrm{Se}, \mathrm{S})_{2}$ photoelectrodes for PEC water splitting has drawn plenty of attention. [41-48]

(a)

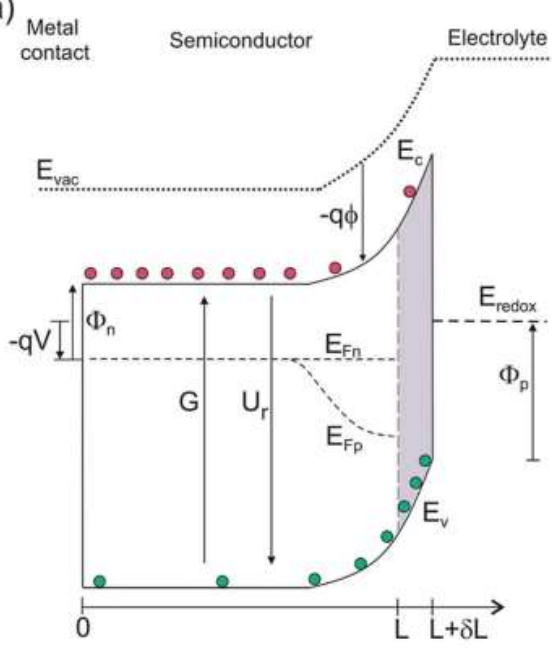

(b)

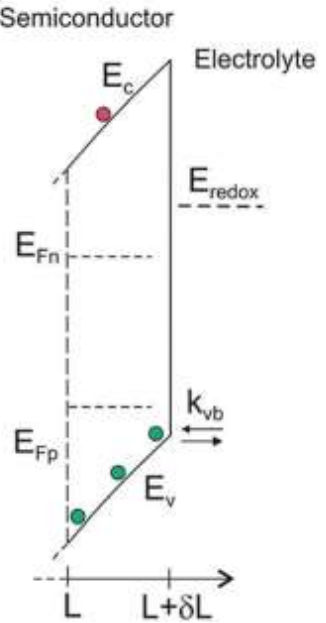

(c)

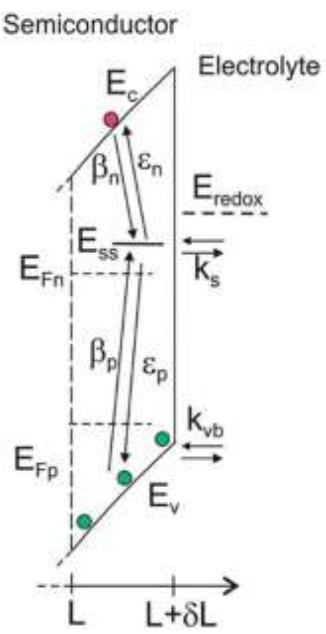

Figure 2. (a) Energy diagrams of an n-type semiconductor of thickness $L$ where electrons and holes are generated at a rate $\mathrm{G}$ and recombine at a rate $\mathrm{U}_{\mathrm{r}}$. At the interface of length $\delta \mathrm{L}$, hole transfer to the redox level $\mathrm{E}_{\text {redox }}$ can take place (b) directly from the valence band (kinetic constant $\mathrm{k}_{\mathrm{vb}}$ ) and (c) indirectly from surface states at low bias and directly from the valence band at higher bias. In this latter model, we consider trapping of electrons and holes $\left(\beta_{\mathrm{n}}\right.$ and $\left.\beta_{\mathrm{p}}\right)$ and detrapping $\left(\varepsilon_{\mathrm{n}}, \varepsilon_{\mathrm{p}}\right)$ and hole transfer from surface states $\left(\mathrm{k}_{\mathrm{s}}\right)$ at the energy level $\mathrm{E}_{\mathrm{ss}}$, in competition with direct hole transfer. In these schemes $\mathrm{E}_{\mathrm{c}}$ and $\mathrm{E}_{\mathrm{v}}$ are the energies of the lower edge of the conduction band and the higher edge of the valence band, respectively. $\mathrm{E}_{\mathrm{Fn}}$ and $\mathrm{E}_{\mathrm{Fp}}$ are the quasi Fermi levels, $\Phi_{\mathrm{n}}$ and $\Phi_{\mathrm{p}}$ are the injection barriers of electrons and 
holes, $E_{\text {vac }}$ is the local vacuum level, $\phi$ is the local electrostatic potential and $\mathrm{V}$ is the applied voltage. Reproduced with permission from ref. [51]

Typically, in photoanodes, surface states can act as recombination centres for holes generated by light, therefore, surface recombination competes intensively with charge transfer from the semiconductor to the electrolyte. Specifically, under illumination, the valence band of a photoanode obtains abundant excess of holes, which can be transferred to the electrolyte by a direct charge transfer mechanism to launch the solar fuel production reaction. However, surface states trap hole carriers, leading to another favourable pathway for indirect charge transfer and a new undesirable recombination pathway. [49-50] A simple kinetic model neglecting any electrostatic influence, like the presence of an electric field has been presented in Figure 2 to show the effect of surface states-assisted electron-hole recombination and indirect charge transfer processes on photoelectrochemical water splitting. At low bias potential, direct holes transfer from the valence band can be neglected and only three processes occur at this interface: trapping/detrapping of electrons, trapping/detrapping of holes and charge transfer of holes. Hence, from this picture, it is clear that surface states-assisted recombination and hole transfer to the solution have a common factor, which is hole trapping/detrapping by surface states. [51-52] Therefore, it is of great interest to distinctly detect the surface states presented at the photoelectrodes and to deeply understand the critical role the surface states play in the PEC water splitting process.

\section{Detecting the Surface States at Hematite via Different Techniques}

\subsection{Photoelectrochemical Impedance Spectrum (PEIS)}

The photoelectrochemical oxygen evolution process on hematite involves the 4 electrons transfer $/ \mathrm{O}_{2}$ molecule. It is hypothesized that the OER reaction steps involve the formation of the higher-valent iron states at the surface by hole capture. Equations (1-4) illustrate the complications arising from the fact that the oxidation of water is a 4electron process, therefore, holes need to be 'stored' in intermediate states. The Fe(IV) and $\mathrm{Fe}(\mathrm{V})$ intermediates in this scheme can also act as electron acceptors, so that surface recombination reactions of the kind shown in equations (5-6) are likely to take place. The Fe(IV) and Fe(V) states can be thought as 'surface-trapped holes', which may have sufficient surface mobility to allow second order reactions of the type illustrated by the last step shown in equations (1-4). [53] 


$$
\begin{aligned}
& \mathrm{hv} \rightarrow \mathrm{h}^{+}+\mathrm{e}^{-} \\
& \mathrm{Fe}(\mathrm{III})_{\text {surf }}+\mathrm{h}^{+} \rightarrow \mathrm{Fe}(\mathrm{IV})_{\text {surf }} \\
& \mathrm{Fe}(\mathrm{IV})_{\text {surf }}+\mathrm{h}^{+} \rightarrow \mathrm{Fe}(\mathrm{V})_{\text {surf }} \\
& 2 \mathrm{Fe}(\mathrm{V})+2 \mathrm{H}_{2} \mathrm{O} \rightarrow 2 \mathrm{Fe}(\mathrm{III})+\mathrm{O}_{2}+4 \mathrm{H}^{+} \\
& \mathrm{Fe}(\mathrm{IV})+\mathrm{e}^{-} \rightarrow \mathrm{Fe}(\mathrm{III}) \\
& \mathrm{Fe}(\mathrm{V})+\mathrm{e}^{-} \rightarrow \mathrm{Fe}(\mathrm{IV})
\end{aligned}
$$

Based on the assumed possible mechanism in equations (1-6), L. M. Peter et al. firstly discussed and derivate the possibility to use the photoelectrochemical impedance spectrum (PEIS) to illustrate the surface states present at the surface of hematite photoanodes, as displayed in Figure 3. [53]
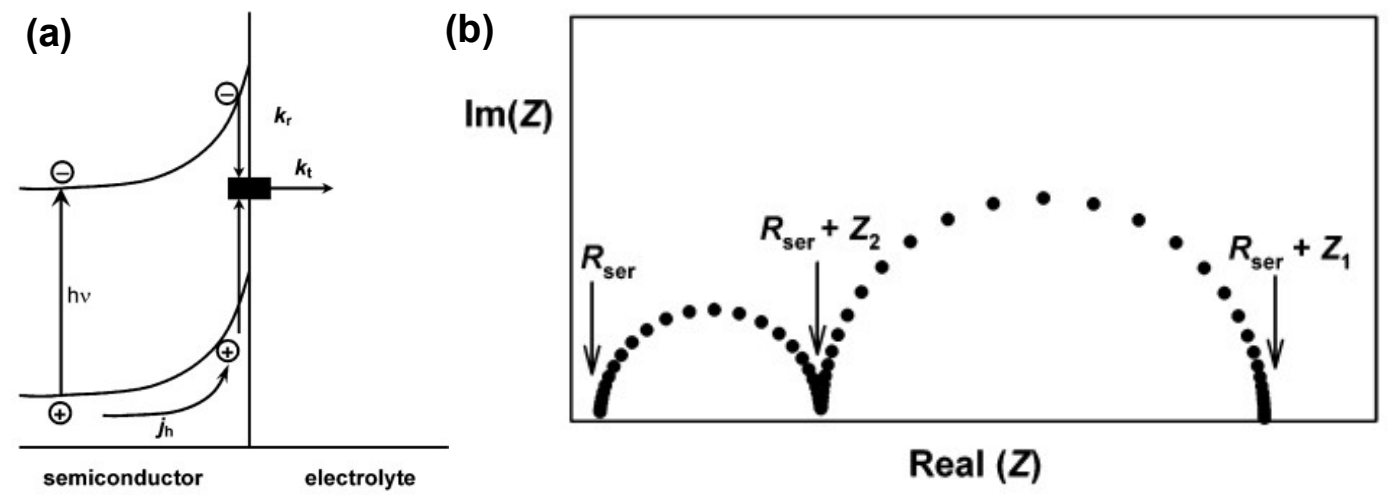

\section{$\operatorname{Real}(Z)$}

Figure 3. (a) Phenomenological kinetic scheme for PEIS analysis. (b) Typical PEIS response predicted by equation (7). Reproduced with permission from ref. [53]

Figure 3a is a simplified version of the model used in the previous discussions to describe the surface states mediated charge transporting in hematite photoanode, which excludes direct hole transfer from the valence band to solution redox; and a typical PEIS response shown in Figure 3b predicted by L. M. Peter et al. based on the derivate of equation (7):

$$
\mathrm{Z}=R_{\text {ser }}+\frac{1}{i \omega C_{s c}+\left(\frac{q}{k_{B} T}\right) j_{h} \frac{k_{r}}{k_{t}+k_{r}} \frac{k_{t}+i \omega}{k_{t}+k_{r}+i \omega}}
$$

Where, $\mathrm{R}_{\mathrm{ser}}$ is the series resistance, $\mathrm{C}_{\mathrm{sc}}$ is the space charge capacitance, $\mathrm{j}_{\mathrm{h}}$ is the current density corresponding to the flux of holes reaching the interface, $\omega$ is the radial frequency. $k_{t}$ and $k_{r}$ are the first order rate constants for interfacial transfer and recombination, respectively. [53]

Furthermore, J. Bisquert and T. Hamann et al. systematically investigated the selection of applicable electrical equivalent circuits for fitting the PEIS data to the interpretation of the surface sates present at photoelectrodes. [54-59] In order to illustrate the PEC 
measurements of the hematite photoanodes under illumination and dark conditions, $\mathrm{J}$. Bisquert and T. Hamann et al. adopted a classical view, as depicted in Figure 4a, to interpret the electrochemical impedance spectrum (EIS) measurements. [60] The equivalent circuit model (ECM) shown in Figure 4b highlights the central role of the surface states acting as a recombination center, trapping electrons from the conduction band and holes from the valence band, as given by $R_{\text {trapping. The surface states affecting }}$ the charge transfer of holes to the donor species in solution are described by $\mathrm{R}_{\mathrm{ct} \text {,trap, }}$ and another pathway for direct charge transfer from the semiconductor bands is included as $\mathrm{R}_{\mathrm{ct}, \mathrm{bulk} .}[54,61]$
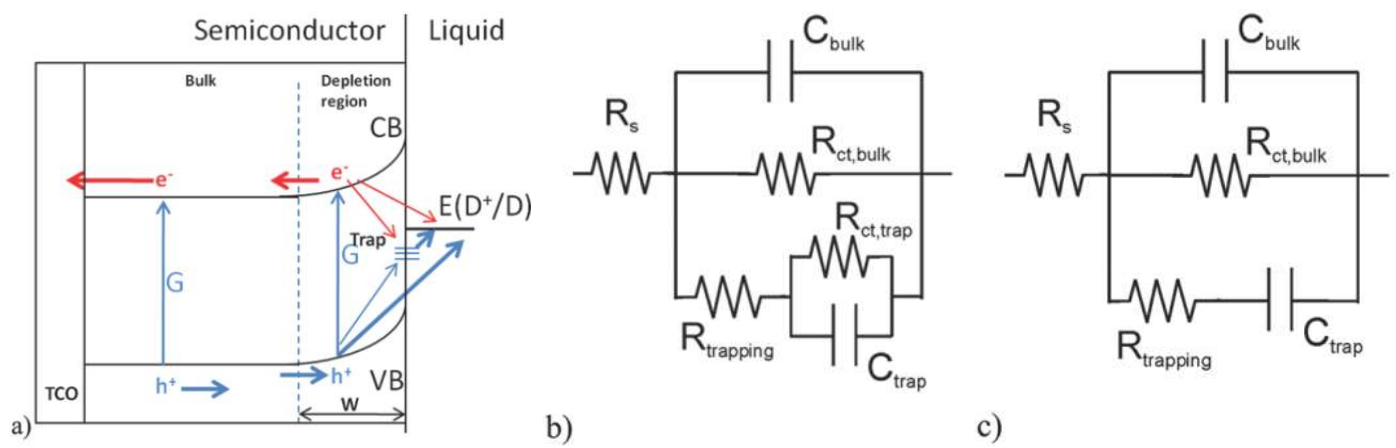

b)

c)

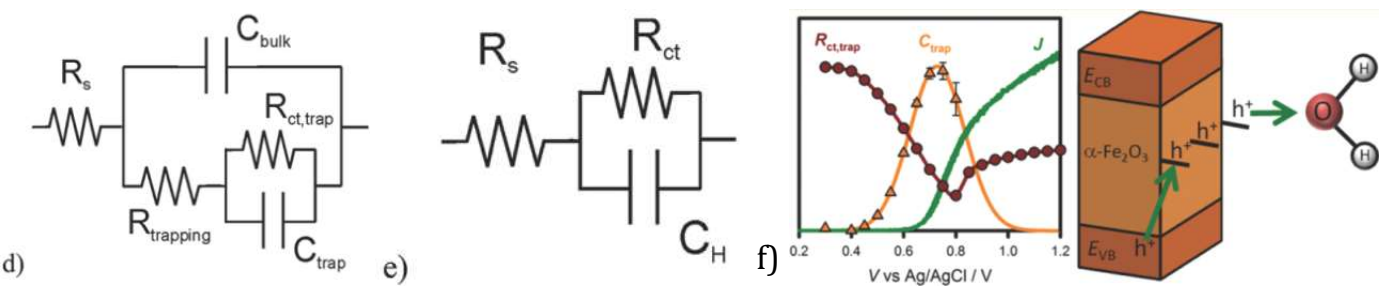

Figure 4. (a) Proposed physical model for the charge carrier dynamics in hematite electrodes, showing their generation, G, by light absorption, surface-state trapping, and interfacial charge-transfer reactions. (b) Equivalent circuit corresponding to the physical model in (a). (c) Simplified model used for IS interpretation created by removing $\mathrm{R}_{\mathrm{ct} \text {,trap. }}$ (d) Simplified model used for IS interpretation created by removing $R_{\text {ct,bulk. }}$ (e) Randles circuit. (f) $\mathrm{J}(\mathrm{V})$ curve (green solid line) and $\mathrm{C}_{\text {trap }}$ (orange triangles) and $\mathrm{R}_{\mathrm{ct} \text {,trap }}$ (red circles) values obtained for a $60 \mathrm{~nm}$ hematite electrode under 1 sun illumination and $\mathrm{pH} 6.9$ with the schematic show the surface state mediate hole transportation at hematite/electrolyte interface. Reproduced with permission from ref. [54]

However, the general ECM proposed in Figure 4b, including the surface-states holetrapping process, cannot unambiguously fit the EIS because it does not discriminate between $R_{c t, b u l k}$ and $R_{c t, t r a p}$. Therefore, two simplifications of this general ECM have been employed, as shown in Figure $4 \mathbf{c}$ and $4 \mathbf{d}$. In these simplifications, either $\mathrm{R}_{\mathrm{ct} \text {,trap }}$ or $\mathrm{R}_{\mathrm{ct} \text {,bulk }}$ is eliminated. The simplified EC are excellent approximations if charge transfer for PEC water oxidation is dominated by one route, either from the valence band (Figure 4c) or surface states (Figure 4d). They fitted the EIS data under illumination with these simplified models and found that more consistent results were obtained for 
the ECM displayed in Figure 4d. [54] Therefore, the simplified ECM in Figure 4d is employed to derive the fitting parameters from all the EIS measurements under illumination for the EIS analysis; while, Randle circuit in Figure 4e is utilized for the fitting of EIS data obtained under dark condition. Figure 4f reveals that the strong correlation between the $\mathrm{C}_{\text {trap }}$ peak with the $\mathrm{R}_{\mathrm{ct} \text {,trap }}$ valley and the photocurrent onset, clearly indicates that the hole-transfer step leading to water oxidation takes place predominantly from surface trapped holes, and not directly from valence band holes. PEIS methodology proposed by J. Bisquert and T. Hamann et al. not only provides new insight into the PEC water oxidation process of pristine hematite photanodes, but also will be of great utility in further investigations of complex hematite composite systems to determine the density and the energy level of the surface states and charge transfer efficiency. [54]

\subsection{Intensity Modulated Photocurrent Spectroscopy (IMPS), Intensity Modulated Photovoltage Spectroscopy (IMVS) and Distribution of Relaxation Times (DRT) Analysis}

IMPS and IMVS are relatively uncommon techniques that probe the dynamic relation between light illumination and the electrochemical response of the photoelectrodes. IMPS is a powerful small amplitude perturbation technique that can deconvolute the rate constants for charge transfer and recombination at illuminated semiconductor electrodes mediated by the surface states. [62-66] L. M. Peter et al. proposed a generalized theoretical model for the intensity modulated photocurrent spectroscopy (IMPS) and derived the analytical equations for the frequency dependence of the photocurrent and photovoltage responses. [62] This theory treats the influence of the space charge, the surface states and the Helmholtz capacitances on the IMPS response. In the model, the charge transfer and recombination at the SEI are described by kinetic equations, whereas the surface states charging and the current through the external circuit are treated using linear circuit equations. [62] In this way, the kinetic constant of the surface states-mediated charge transfer and charge recombination in the photoelectrodes system can be readily obtained from the IMPS plot. IMVS is conceptually similar to IMPS, but it is not as popular as IMPS as a measurement technique. It probes the relationship between light intensity and photovoltage at constant photocurrent response. These photoelectrochemical immittance triplets (PIT), consisting of three electrochemical techniques (PEIS, IMPS and IMVS) based on 
electrochemical impedance and optical modulation used to probe the dynamic performance of photoelecttrodes for PEC water splitting have been mathematically and phenomenologically compared by A. Rothschild et al. [67]

In addition to these established PIT analysis methods, there is another approach, DRTbased empirical analysis, which is a distribution function that can be calculated for any impedance spectrum without any a priori assumption. [67-68] The most useful characteristic of DRT analysis is its capability to separate polarization processes more clearly than in common Nyquist or Bode plots, where they usually appear convoluted. Since it circumvents the construction of ECM, which always depend on presumptions and are never unique, DRT analysis is a powerful tool to support impedance data analysis. [67-68] For instance, A. Rothschild et al. employed DRT analysis to study hematite photoanodes in alkaline electrolytes, where they identified two dominant polarization processes: The first process is surface recombination, which is dominant at low potentials and is suppressed by adding hole scavenger $\left(\mathrm{H}_{2} \mathrm{O}_{2}\right)$ to the electrolytes; The second process is suspected to be the formation of double-bonded oxygen intermediates $(\mathrm{Fe}=\mathrm{O})$, which dominates the water oxidation reaction at high potentials (without $\mathrm{H}_{2} \mathrm{O}_{2}$ ) and the $\mathrm{H}_{2} \mathrm{O}_{2}$ photo-oxidation reaction at all potentials. [68-69]

\subsection{Cyclic Voltammetry}
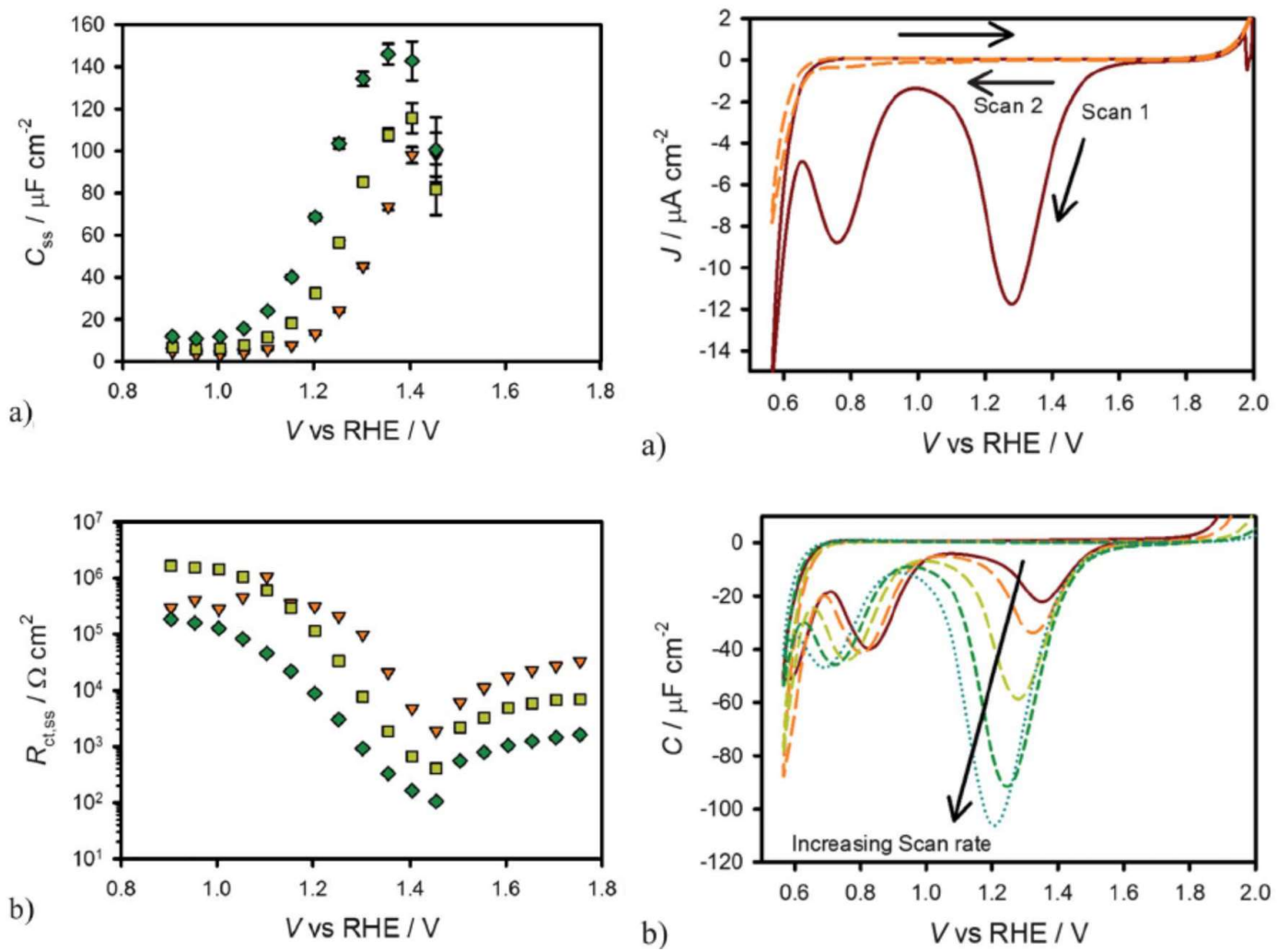
Figure 5. Left: Equivalent circuit parameters obtained from fitting EIS data for a hematite electrode in contact with $\mathrm{H}_{2} \mathrm{O}$ ( $\mathrm{a}$ and $\mathrm{b}$ ) under 0.1 sun (orange triangles), 0.33 sun (yellow squares) and 1 sun (green diamonds) illuminations. Right: (a) Cyclic voltammetry of hematite in $\mathrm{H}_{2} \mathrm{O}$ scanned at $200 \mathrm{mV} \mathrm{s}^{-1}$ after holding the electrode at a potential of $2 \mathrm{~V}$ vs. RHE for 60 seconds under 1 sun illumination. The first cycle is a solid red line and the second cycle is a dashed orange line. (b) CVs measured with the same conditions as (a) at different scan rates: $20 \mathrm{mV} \mathrm{s}^{-1}$ (red, solid), $50 \mathrm{mV} \mathrm{s}^{-1}$ (orange, long dash), $200 \mathrm{mV} \mathrm{s}^{-1}$ (yellow, medium dash), $500 \mathrm{mV} \mathrm{s}^{-1}$ (green, short dash) and $1000 \mathrm{mV} \mathrm{s}^{-1}$ (blue, dots). Reproduced with permission from ref. [63]

T. W. Hamann et al. demonstrated that the surface states trapped holes in hematite photoanodes could be measured by using cyclic voltammetry in the dark. [63] Specifically, holes could accumulate on the hematite photoanodes surface by applying a positive potential under illumination followed by measuring the cathodic current in the dark as the potential is scanned negatively and the surface states are reduced. As shown in Figure 5, the cathodic current peak observed in the dark cyclic voltammetry scan is well consistent with the $\mathrm{C}_{\mathrm{ss}}$ peak obtained in the fitted EIS data, indicating the presence of surface states in hematite photoanodes. [63]

\subsection{Operando UV-vis}
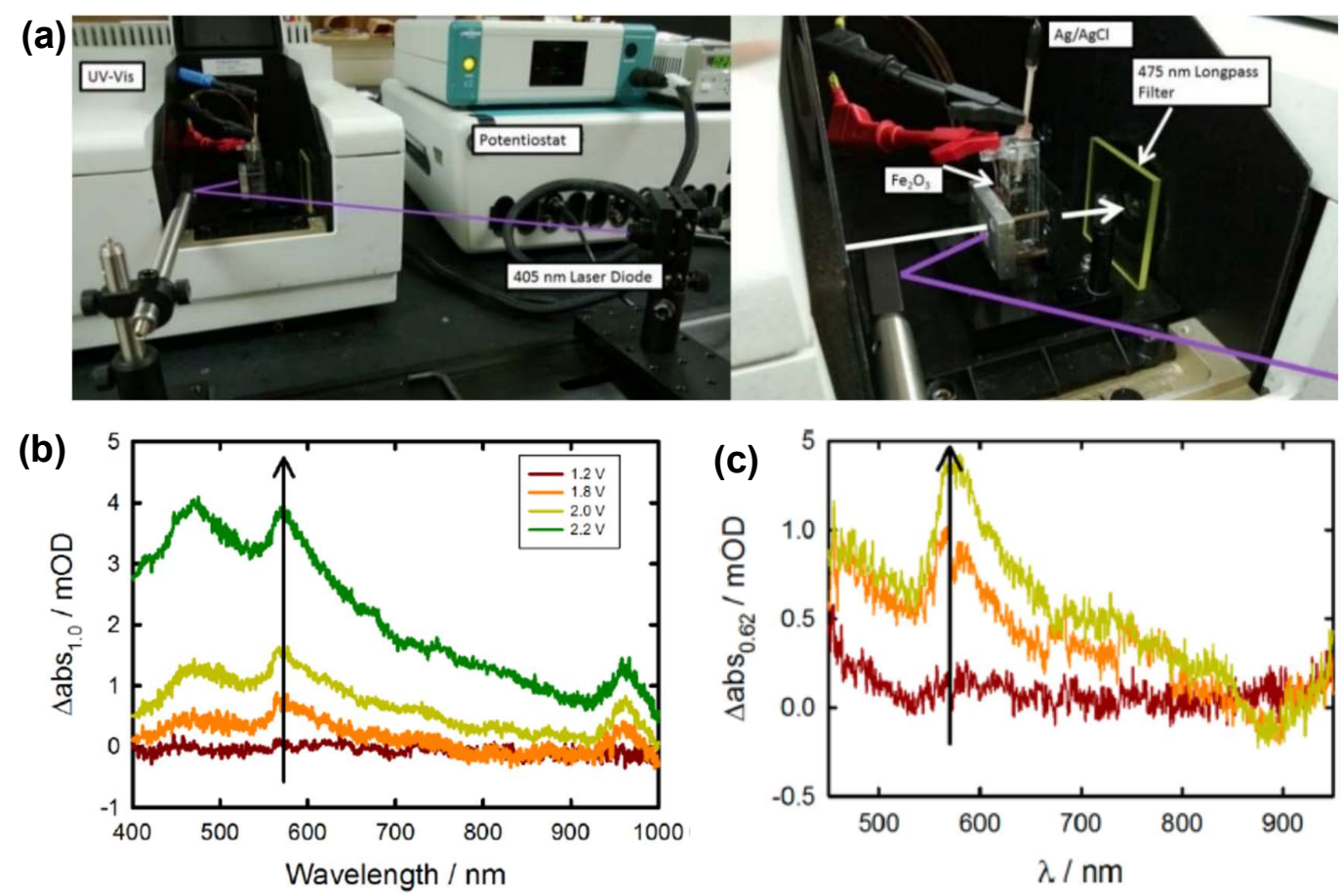

Figure 6. (a): Experimental setup of spectroelectrochemical measurements performed under monochromatic illumination. (b): Change in absorption spectra measured vs $1.0 \mathrm{~V}$ vs RHE. Spectra measured in the dark and under applied potentials of 1.2 (red line), 1.8 (orange line), 2.0 (yellow line) and 2.2 (green line) V vs RHE. (c): Change in absorption spectra measured at $0.82 \mathrm{~V}$ (red), $1.22 \mathrm{~V}$ (orange), and $1.62 \mathrm{~V}$ versus RHE (yellow) measured under $0.1 \mathrm{~mW} \mathrm{~cm} \mathrm{~cm}^{-2} 405 \mathrm{~nm}$ illumination with respect to the absorption spectra measured at $0.62 \mathrm{~V}$. Reproduced with permission from ref. [70]

Considering that the hematite surface plays a significant role in determining the efficiency of water oxidation, it is of great interest to directly identify the identity of the 
relevant hematite surface species via in-situ techniques to evidence the surface states mediated charge transfer mechanism hypotheses. T. Hamann and H. Irie et al. detected the intermediate species during oxygen evolution reaction via in-situ UV-vis absorption spectra (Figure 6a) for atomic layer deposition and sprayed prepared hematite photoanodes. [70-71] For instance, T. Hamann et al. quantitatively measured the formation of the Fe (IV) intermediate by integrating the absorption peak at $572 \mathrm{~nm}$ via operando UV-vis experiments, as displayed in Figure $\mathbf{6 b}$ and $\mathbf{6 c}$; The absorption features at $572 \mathrm{~nm}$ could be correlated with the $\mathrm{C}_{\mathrm{ss}}$ obtained in PEIS, which is assigned to the oxidation of a low-valent $\mathrm{Fe}-\mathrm{H}_{2} \mathrm{O}$ or $\mathrm{Fe}-\mathrm{OH}$ to a high-valent $\mathrm{Fe}=\mathrm{O}$ group at the hematite photoanode surface.[70] Additionally, the coating of a single layer of alumina by atomic layer deposition onto the bare hematite photoanode reduced the UV-vis absorption features because there are fewer exposure iron atoms at the hematite surface, fewer iron hydroxyls are able to be generated upon oxidation by a photogenerated hole. [70]

\subsection{In-Situ Infrared (IR) Spectroscopy}
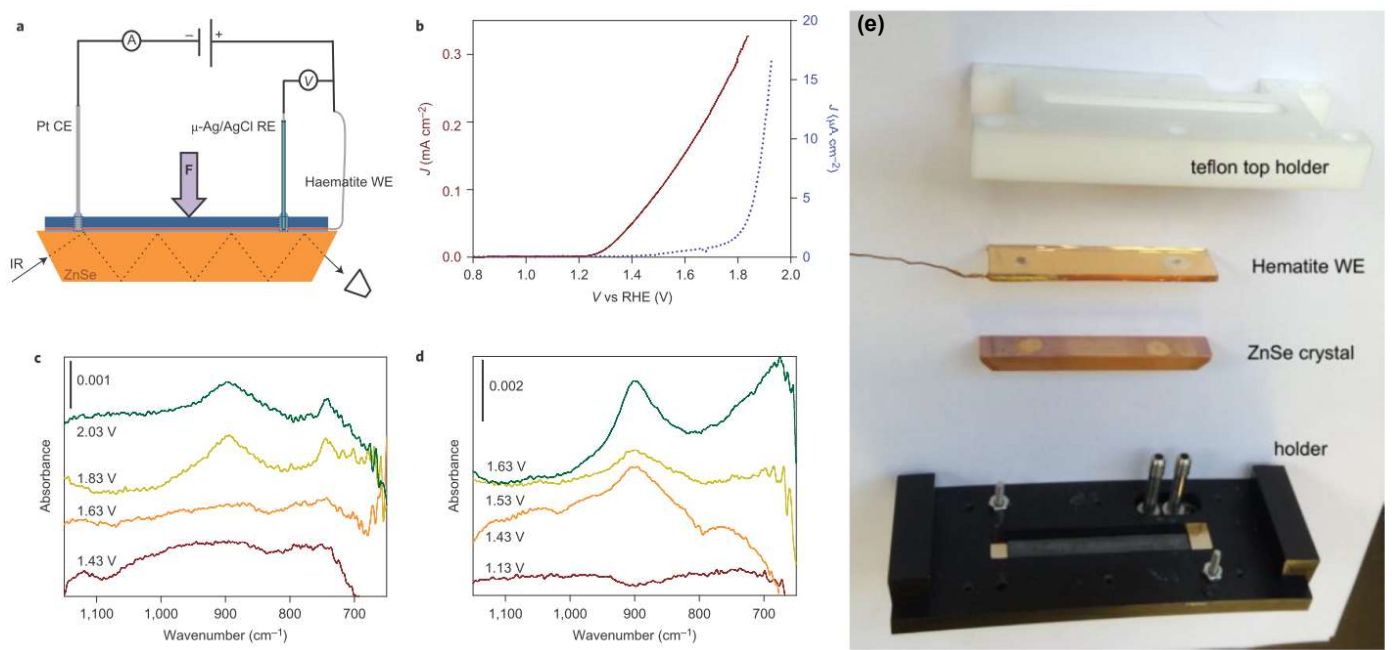

Figure 7. Experimental set-up and results of infrared spectroscopy measurements during electrochemical and PEC water oxidation. (a) This schematic of the set-up used for operando PEC infrared (IR) measurements depicts the hematite working electrode (WE), platinum counter electrode (CE), $\mathrm{Ag} / \mathrm{AgCl}$ reference electrode (RE) and ZnSe ATR crystal. A thin layer of electrolyte was introduced between the hematite WE and the ATR crystal. (b) J-V curves of a hematite electrode in the operando PEC infrared set-up measured in contact with $\mathrm{D}_{2} \mathrm{O}$ in the dark (blue) and under illumination (dark red). (c) Infrared spectra of hematite scanned at constant applied potentials, from 1.43 to $2.03 \mathrm{~V}$ versus RHE, in the dark. (d) Infrared spectra of hematite scanned at constant applied potentials, from 1.13 to $1.63 \mathrm{~V}$ versus RHE, under illumination. Peaks at 898 and $743 \mathrm{~cm}^{-1}$ appear at potentials positive to the onset of the wateroxidation current, $1.7 \mathrm{~V}$ versus RHE in the dark and $1.25 \mathrm{~V}$ versus RHE under illumination, which indicates that they may be species involved in the water-oxidation reaction. (e) The ATR-IR cell assembly parts. Reproduced with permission from ref. [72] 
It is well established that infrared spectroscopy is a powerful technique for the determination of intermediate species in catalytic reactions. [72-76] Additionally, the utilization of attenuated total reflectance infrared (ATR-IR) spectroscopy is supposed to overcome challenges including the low concentration of intermediates on electrode surfaces and the competitive infrared absorption by water. [75] T. Hamann et al. investigated the water-oxidation reaction on hematite via in-situ ATR-IR spectroscopy, and directly observed the existence of the $\mathrm{Fe}^{\mathrm{IV}}=\mathrm{O}$ intermediate during the PEC water splitting process, as shown in Figure 7. [72] As displayed in Figure 7(c) and 7(d), a potential- and light-dependent absorption peak presented at $898 \mathrm{~cm}^{-1}$ vis in-situ ATR-IR spectroscopy is assigned to a $\mathrm{Fe}^{\mathrm{IV}}=\mathrm{O}$ group, which is an intermediate in the $\mathrm{PEC}$ water oxidation reaction. These results provide direct evidence of high-valent iron-oxo intermediates as the product of the first hole transfer reaction on the hematite surface and represent an important step in establishing the mechanism of PEC water oxidation on semiconductor electrodes. [72] J. C. Zhao et al. investigated the reaction order of interfacial hole transfer by rate law analysis based on EIS measurements and probed the high-valent $\mathrm{Fe}^{\mathrm{IV}}=\mathrm{O}$ intermediates by operando Fourier-transform infrared (FT-IR) spectroscopy, finding that in highly alkaline electrolytes, coupling of adjacent surface trapped holes becomes the dominant mechanism with a reaction orders of $\sim 2$. [76]

\subsection{Dimensions Transmission electron microscope (4D TEM)}

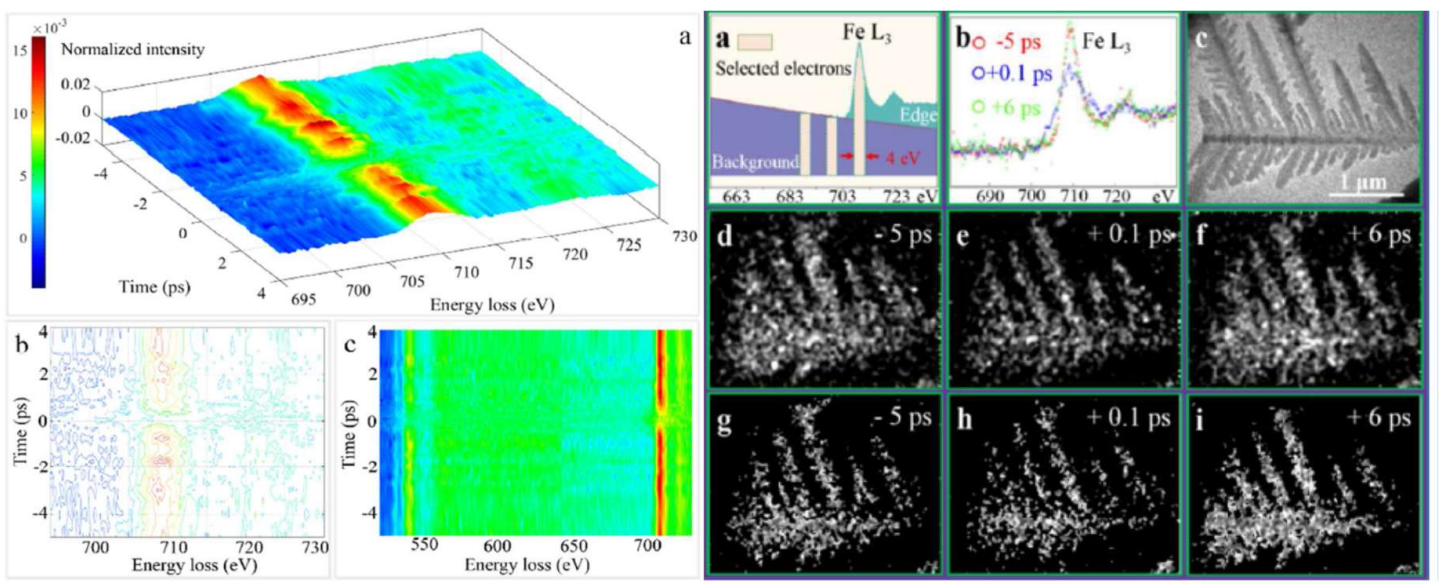

Figure 8. Left: (a) 3D intensity-energy-time dynamics of the overall Fe L-edge FEELS. (b) Intensity contour map of (a). (c) Top view of Fe L3-edge (above $700 \mathrm{eV}$ ) and O K-edge (around $540 \mathrm{eV}$ ) FEELS. Right: (a) Electrons centred at 709.5, 699.5 and $689.5 \mathrm{eV}$ energy loss are selected by a slit window of 4 $\mathrm{eV}$ for the elemental mapping and the jump-ratio images. (b) Time-dependent EELS of Fe L3-edge with background subtracted. (c) Ultrafast TEM image of a typical $\mathrm{Fe}_{2} \mathrm{O}_{3}$ particle without energy filtering. Temporal change of iron elemental mapping images (d-f) and jump-ratio images (g-i) of the $\alpha-\mathrm{Fe}_{2} \mathrm{O}_{3}$ particle obtained by a three-window method with two pre-edge $(699.5 \pm 2 \mathrm{eV}, 689.5 \pm 2 \mathrm{eV})$ and one post-edge $(709.5 \pm 2 \mathrm{eV})$, and a two-window method with one pre-edge $(699.5 \pm 2 \mathrm{eV})$ and one postedge $(709.5 \pm 2 \mathrm{eV})$, respectively. Reproduced with permission from ref. [77] 
Nonetheless, the aforementioned mechanism investigations of hematite based photoanodes are limited to obtain macroscopic information of the $\mathrm{Fe}^{\mathrm{IV}}=\mathrm{O}$ intermediates via in-situ spectroscopies, like UV-Vis, in-situ ATR-IR spectroscopy, PEIS, IMPS, IMVS, and DRT, but without spatially disclosing the location of the surface intermediates or active sites. [78] The shortage of an accurate spatial identification of the OER active sites $\left(\mathrm{Fe}^{\mathrm{IV}}=\mathrm{O}\right)$ in hematite photoanodes currently hinders the clear determination of the OER mechanism of hematite photoanodes for water splitting. Recently, by employing core-loss electron energy loss spectroscopy (EELS) signals (of several hundred $\mathrm{eV}$ ), coupled to femtosecond temporal resolution as well as ultrafast energy-filtered 4D TEM, A. H. Zewail et al. have identified that $\mathrm{Fe}^{\mathrm{IV}}=\mathrm{O}$ has a lifetime of a few picoseconds, the associated photoinduced electronic transitions and charge transfer processes in hematite photocatalyst, as shown in Figure 8. [77] It demonstrates that the direct observation of $\mathrm{Fe}^{\mathrm{IV}}=\mathrm{O}$ intermediates at hematite photoanodes with spatial, temporal and energy resolution is possible via 4D TEM.

\subsection{Density Functional Theory (DFT)}
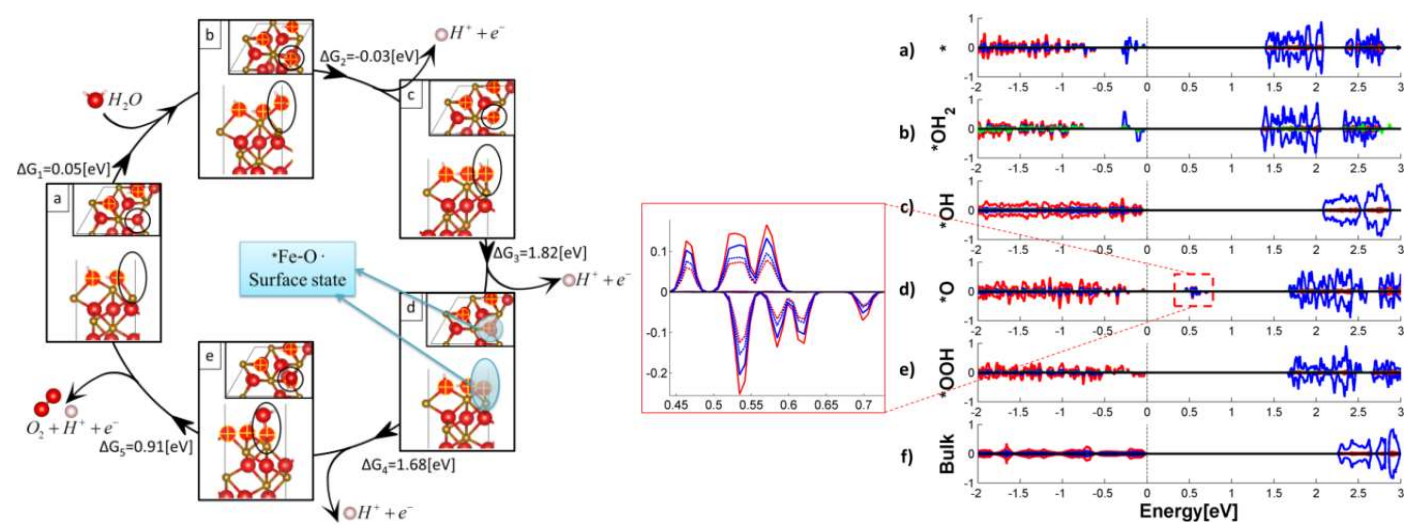

Figure 9. Left: Intermediates and free energies at zero bias for water oxidation over pure $\mathrm{Fe}_{2} \mathrm{O}_{3}(0001)$. In the frames, side and top view of the intermediates surface: (a) $* \mathrm{vac}$, (b) $* \mathrm{OH}_{2},(\mathrm{c}) * \mathrm{OH},(\mathrm{d}) * \mathrm{O}$, and (e) $* \mathrm{OOH}$. Spheres in red, gold, and white represent $\mathrm{O}, \mathrm{Fe}$, and $\mathrm{H}$ atoms, respectively. Marked in yellow are the surface oxygen atoms. The location of the active site with adsorbates is circled in black. The location of the surface state is circled in blue at the ${ }^{*} \mathrm{O}$ intermediate. Right: Projected density of states (PDOS) of five water oxidation intermediates of the pure $\mathrm{Fe}_{2} \mathrm{O}_{3}(0001)$ surface: (a) *vacancy, (b) $* \mathrm{OH}_{2}$, (c) $* \mathrm{OH}$, (d) $* \mathrm{O}$, (e) ${ }^{*} \mathrm{OOH}$ intermediates, and (f) bulk $\mathrm{Fe}_{2} \mathrm{O}_{3} . \mathrm{O}, \mathrm{Fe}$, and $\mathrm{H}$ total DOS is in red, blue, and green plain lines, respectively. Enlarged is the mid-gap states for the $* \mathrm{O}$ intermediate, with the $\mathrm{p}$ orbital of $\mathrm{O}$ atom at the active site and the $\mathrm{d}$ orbital of the neighbouring Fe atom in red and blue broken lines, respectively. DOS is normalized to a maximum total density of one. Reproduced with permission from ref. [80]

Some other theoretical researchers investigated the nature of surface states in hematite based photoanodes via DFT calculations. [79-81] B. Iandolo et al. investigated the surface states on hematite under photoelectrochemical conditions and calculated the density of states for two relevant hematite atomic terminations via DFT calculations, 
where the presence and the role of surface states was rationalized. It predicted a Nerstian dependence on the OER onset potential on $\mathrm{pH}$, which was to a very good extent confirmed by PEC measurements and EIS characterization.[79] Meanwhile, M. C. Toroker et al. performed first-principles calculations with DFT $+U$ on several possible adsorbates at the $\alpha-\mathrm{Fe}_{2} \mathrm{O}_{3}(0001)$ surface, ruling out the existence of a stable peroxo Fe$\mathrm{O}-\mathrm{O}-\mathrm{Fe}$ adsorbate. They demonstrated that the origin of the surface absorption peak at $580 \mathrm{~nm}$ could be a $\mathrm{Fe}-\mathrm{O}$. type bond that acts as an essential intermediate for water oxidation; the projected density of states (PDOS) of the ${ }^{*} \mathrm{O}$ intermediate shows a midgap state, which is located far below the conduction band edge, but close to the valence band edge, as shown in Figure 9. [80]

\subsection{Scanning Electrochemical Microscopy (SECM)}

SECM is a versatile electrochemical platform used in the characterization of electrocatalysts and photoelectrodes to collect products and measure electron transfer kinetics, which is useable in the PEC water splitting field. [82-84] For instance, A. J. Bard et al. employed surface interrogation scanning electrochemical microscopy (PEC SI-SECM) for the quantitative determination of the reaction intermediates, where a light pulse to a hematite film at a given potential generates intermediates that are then analysed by a tip generated titrant at known times after the light pulse. [83] The density of photoactive sites on a hematite surface, proposed to be $\mathrm{Fe}^{4+}$ species in a redox titration, was successfully quantified to be $18 \mathrm{Fe}$ atoms $\mathrm{nm}^{-2}$; the pseudo-first order reaction rate constants were determined as 0.03 to $0.19 \mathrm{~s}^{-1}$ based on time-dependent redox titration experiments. [83]

\subsection{Kinetic Isotope Effect (KIE)}

Understanding the mechanism of water oxidation to $\mathrm{O}_{2}$ represents the bottleneck towards the design of efficient PEC water splitting device. It is well established that water oxidation on hematite is mediated by surface trapped holes, characterized to be the high valent $-\mathrm{Fe}=\mathrm{O}$ species. However, the mechanism of the subsequent rate-limiting $\mathrm{O}-\mathrm{O}$ bond formation step is still a missing piece. Recently, the mechanistic studies of the water oxidation at hematite photoanodes via kinetic isotope effects have drawn researchers's attention. [76, 85-86] For instance, J.C. Zhao et al. demonstrated the pivotal role of proton transfer in water oxidation on hematite photoanodes using PEC 
characterization, the H/D kinetic isotope effect, and PEIS. They found that the ratedetermining interfacial hole transfer to water molecules at the hematite surface is a concerted proton-electron transfer process at $\mathrm{pH}<12$. A mechanistic transition in the rate-determining step from concerted proton-electron transfer (CPET) to electron transfer (ET) occurred after $\mathrm{OH}^{-}$became the dominant hole acceptor. [85]

\section{Engineering of Surface States at Hematite Photoanodes}

\subsection{Intrinsic Modification Engineering}

\subsubsection{Sintering Parameters}

(a)

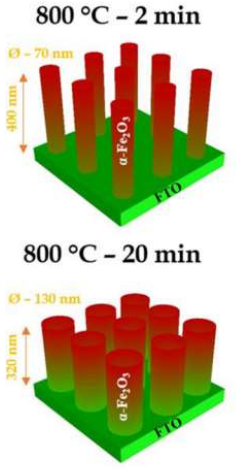

$800^{\circ} \mathrm{C}-10 \mathrm{~min}$

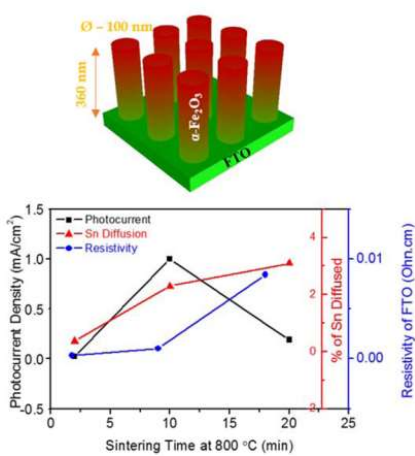

(b)

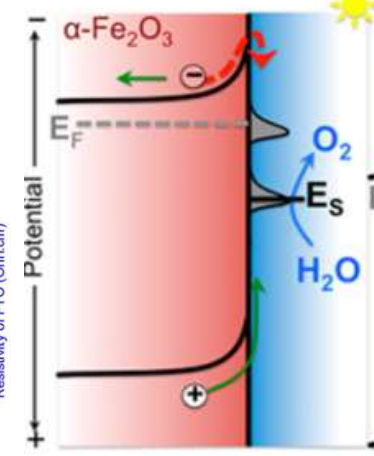

Annealed at $800^{\circ} \mathrm{C}$ $\alpha-\mathrm{Fe}_{2} \mathrm{O}_{3}$

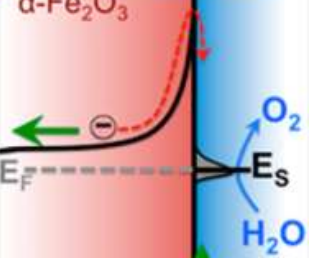

Figure 10. (a): Activation of hematite photoanodes by high-temperature sintering entails a kinetic competition between Sn dopant diffusion from the FTO substrate into the hematite, and the resulting thermal deformation and conductivity loss in the FTO substrate. Reproduced with permission from ref. [89] (b): Simplified band diagram of hematite electrodes under conditions with (left) and without (right) Fermi level pinning by the sub-conduction band surface states. Reproduced with permission from ref. [90]

The sintering parameters, including temperature, period and atmosphere, play a vital role in the PEC performance of hematite based photoanodes because it is supposed to reduce the crystal defects, to affect the donor density via Sn doping from FTO substrates, to create oxygen vacancies $\left(\mathrm{V}_{\mathrm{o}}\right)$ or to modify the surface states of the photoelectrodes. [87-99] For instance, J. S. Jang et al. examined the role of FTO deformation during the activation of hematite photoanodes on FTO substrates, as displayed in Figure 10a. [89] The incorporation of Sn dopants from the FTO substrates in the hematite lattice was confirmed by X-ray photoelectron spectroscopy and was found to increase with sintering time. Specifically, under $800{ }^{\circ} \mathrm{C}$ annealing, the FTO substrates underwent a stoichiometric change that directly affected their electrical conductivity; their resistivity was doubled after 20 min of sintering at $800{ }^{\circ} \mathrm{C}$. Activation of hematite photoanodes by high-temperature sintering entails a kinetic competition between Sn dopant diffusion from the FTO substrate into the hematite and 
the resulting thermal deformation and conductivity loss in the FTO substrates. [89] Therefore, the increasing photocurrent response is attributed to the enhanced $\mathrm{Sn}$ doping and thus the improved donor density in the hematite based photoanodes. [87-89]

It is reported that controlling the sintering temperature may not only induce the Sn diffusing into the hematite matrix, but also alter the surface states present at the surface of the hematite based photoanodes. [90-94] For instance, T. W. Hamann et al. demonstrated that annealing hematite at $800{ }^{\circ} \mathrm{C}$ substantially improves the water oxidation efficiency of the ultrathin film hematite electrodes, which is ascribed to the removal of the surface states close to the conductance band of the hematite photoanodes and the reducing recombination and Fermi level pinning, as displayed in Figure 10b.[90] Moreover, Y. Li et al. reported a novel fire treatment, which was adopted to activate two types of hematite photoanodes (sol-gel thin films and hydrothermal nanowires), which successfully removed the surface trap states (surface hydroxyls) on hematite and thus resulted in an optimized photocurrent density of $2.63 \mathrm{~mA} \mathrm{~cm}^{-2}$.[92] Additionally, Y. D. Li et al. found that the cooling rate during the sintering process is an important factor deciding PEC water splitting of hematite photoanodes. Rapid cooling of the hematite photoanodes increased the photocurrent from $0.635 \mathrm{~mA} \mathrm{~cm}{ }^{-2}$ for the normally cooled sample to $0.856 \mathrm{~mA} \mathrm{~cm}^{-2}$ at $1.23 \mathrm{~V}$ vs. RHE. The rapidly cooled

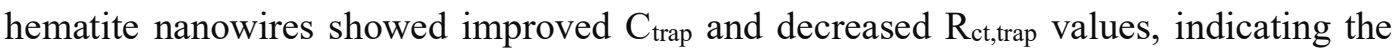
improvement of the hole transfer capability and the acceleration of the surface charge transfer via modifying the surface states, respectively.[93]

On the other hand, sintering atmosphere is another important parameter that might affect the PEC performance of hematite photoanodes. It is well established that oxygen vacancies $\left(\mathrm{V}_{\mathrm{o}}\right)$ in hematite photoanodes can be readily obtained via sintering the electrodes in oxygen deficient atmosphere. [95-97] Y. Li et al. reported a novel method for the preparation of highly conductive hematite photoanodes through thermal decomposition of $\mathrm{FeOOH}$ in an oxygen-deficient atmosphere $\left(\mathrm{N}_{2}+\right.$ air). The latest showed substantially enhanced photoactivity compared to the pristine hematite prepared in air. The oxygen content during thermal activation significantly affects the formation of $V_{o}$ and thus the photoactivity of hematite nanowires for PEC water oxidation. [95-96] While, A. J. Cowan et al. proposed that $\mathrm{V}_{\mathrm{o}}$ may act as a 'mixed blessing', with the enhanced electrical properties being balanced with a potential increase in trap-mediated electron-hole recombination at the surface defect sites introduced. [96] Recently, L. Z. Wang et al. obtained comprehensive analysis for the key charge transfer and surface 
reaction steps in PEC processes on hematite photoanodes to understand the $\mathrm{V}_{\mathrm{o}}$ role in hematite photoanodes. Moreover, they also clarified that $\mathrm{V}_{\mathrm{o}}$ can facilitate the surface electrocatalytic processes while leading to severe interfacial recombination at the semiconductor/electrolyte interface, in addition to the well-reported improvements in bulk conductivity. [97] Additionally, $\mathrm{H}_{2}$ treatment during the sintering process could introduce vacancies as well as mid-gap states in the photoactive semiconductor for water splitting. [98-100] For instance, G. A. Ozin et al. presented a mean of activating hematite towards to PEC water splitting via thermal treatment of ultrathin films of hematite under an atmosphere of $5 \% \mathrm{H}_{2}$, it was determined that $\mathrm{V}_{\mathrm{o}}$ is the most likely structural change following hydrogen treatment. Surface states analyses using electrochemical techniques revealed a probable change in the mechanism of PEC water oxidation as well as the appearance of a new surface states coincident with the onset of photocurrent. [99]

\subsubsection{Acid/Alkali Media Surface Treatments}

It has been reported that the surface states of hematite electrodes can be modified via treating the hematite photoanodes in acidic or alkaline media, leading to enhanced charge separation efficiency and thus improved PEC water splitting performance. [101103] Y. Li et al. investigated the effect of acidic media (including acetic acid, $\mathrm{HCl}$, $\mathrm{HNO}_{3}$, and $\mathrm{H}_{3} \mathrm{PO}_{4}$ ) treatment on hematite photoanodes. They demonstrated that a simple acid treatment method modify either the nature or position of the available trap sites, which substantially enhance the efficiency of electrons moving out of traps in hematite nanowire photoanodes, and thus reduce the electron-hole recombination loss and improve PEC performance. [101] Meanwhile, J. H. Ye et al. found that the photocurrent densities increased 3- and 2-times for $\alpha-\mathrm{Fe}_{2} \mathrm{O}_{3}$ and $\mathrm{Ti}: \alpha-\mathrm{Fe}_{2} \mathrm{O}_{3}$ photoanodes after $\mathrm{KOH}$ treatment, respectively. They demonstrated that a conformal thin layer grafted with hydroxyl $(-\mathrm{OH})$ groups was formed on the hematite surface, which behaved like an electrocatalyst to accelerate the water oxidation kinetics on hematite photoanodes. [102]

\subsubsection{Re-growth}

Disordered hematite structures can be synthesized at low cost and large scale, however, they typically suffer from charge recombination and poor PEC water splitting 
performance. Additionally, the structural disorders on or near the hematite surfaces are important causes of the low photovoltages. Recent investigations reveal that the surface disordered hematite structures can be overcome by re-growth strategy, which pave the way for producing efficient photoanodes based on hematite.[104-105] For instance, D. W. Wang et al developed a facile regrowth strategy to reduce surface disorders and as a consequence, a turn-on voltage of $0.45 \mathrm{~V}$ (versus reversible hydrogen electrode) was achieved.[104] Moreover, A. Tricoli et al. employed capillary force-induced restructuring and chemically-induced re-growth methods, to drastically increase the photocurrent by 24 times from $0.032 \mathrm{~mA} \mathrm{~cm}^{-2}$ of the initial disordered hematite photoanodes to $0.79 \mathrm{~mA} \mathrm{~cm}^{-2}$ at $1.23 \mathrm{~V}$ vs. RHE under simulated 1 sun irradiation.[105]

\subsection{Extrinsic Engineering}

\subsubsection{Doping/A Secondary Semiconductor Coating}

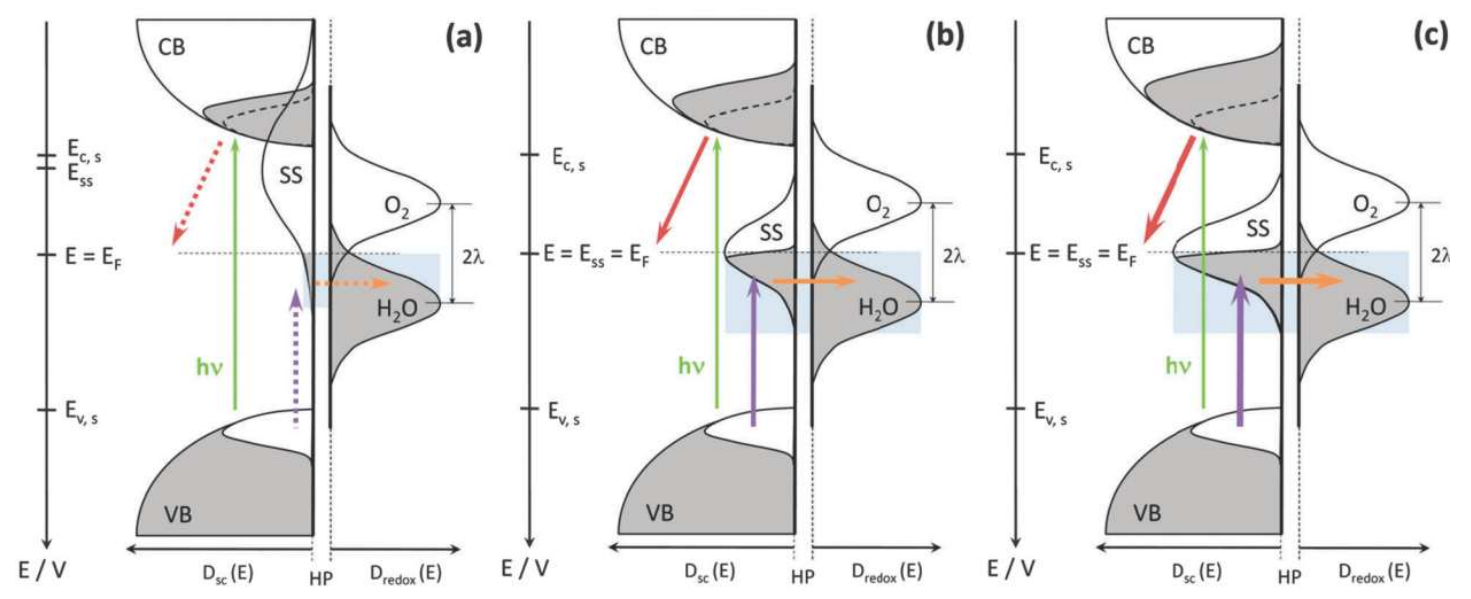

Figure 11. Kinetic scheme of the charge generation and transfer processes at the biased (1.23 $\left.\mathrm{V}_{\mathrm{RHE}}\right)$ semiconductor electrolyte interface (SEI) under illumination and for different titania doping levels, including: (a) no doping (0\%), (b) low or large doping (5\% and/or 20\%) and (c) optimum doping (10$15 \%)$. Grey and white areas refer to electron filled or empty states, respectively. The dotted lines inside the conduction band $(\mathrm{CB})$ filled states denote photogenerated electrons with the same relative area than the empty states at the valence band (VB); the exceeding grey areas highlight the bulk (core) doping levels, which are shown intentionally oversized for comparison purposes. The green arrow refers to the charge generation process upon visible photons absorption (hv); the purple arrow refers to the hole trapping process at surface states (SS); the orange arrow refers to the hole transfer process from SS to water molecules; the red arrow refers to (photo)electron transfer from semiconductor $\mathrm{CB}$ states to the underlying conducting substrate (FTO). The thickness and shape of the arrows indicate the relative rates of the charge transfer processes, where the dotted line represents the slowest rate (a) and the thickest line represents the fastest rate (c). The light blue shaded areas refer to the relative overlapping of the SS and water density of states (DOS). Note that the relative size of the SS distribution for the non-doped sample (a) has been intentionally enlarged to highlight the overlapping between the semiconductor and the redox couple states. $\mathrm{D}_{\text {redox }}$ : normalized DOS of the redox couple in the electrolyte; $\mathrm{D}_{\text {sc }}$ : DOS of the semiconductor; $\mathrm{E}$ : electrode potential; $\mathrm{E}_{\mathrm{c}, \mathrm{s}}$ : surface $\mathrm{CB}$ edge potential; $\mathrm{E}_{\mathrm{F}}$ : Fermi level of the semiconductor that matches the electrode potential (E) and the $\mathrm{O}_{2} / \mathrm{H}_{2} \mathrm{O}$ couple thermodynamic potential $\left(1.23 \mathrm{~V}_{\mathrm{RHE}}\right)$; $\mathrm{E}_{\mathrm{SS}}$ : center potential of the SS distribution; $\mathrm{E}_{\mathrm{v}, \mathrm{s}}$ : surface VB edge potential; HP: Helmholtz 
plane at the SEI, across which the charge transfer process occurs; 1: redox couple reorganization energy. Reproduced with permission from ref. [117]

Plenty of attention has been drawn to the development of composite hematite photoanodes with doping or secondary semiconductors, to further enhance the PEC water oxidation efficiency. [106-116] Meanwhile, other researchers spared no effort in correlating PEC performance improvement with the surface states evolution upon doping or coating of a secondary semiconductor onto hematite photoanodes. [117-128] For instance, D. Monllor-Satoca et al. prepared mesoporous hematite-titania composite films by mixing the respective preformed nanoparticles obtained by a non-aqueous solgel route in a wide range of loading levels (0-20 mol \%). Voltammetric and EIS were performed observing an optimum 10\% doping, with a 15-fold photocurrent increase (up to $1.3 \mathrm{~mA} \mathrm{~cm}^{-2}$ at $1.23 \mathrm{~V}$ vs RHE) and a 100 -fold decrease of the charge transfer resistance. The roles of surface states and donor densities were highlighted, assuming a charge transfer mechanism through hole trapping at surface states and its isoenergetic transfer to water; an optimum 10-15\% doping range was obtained, where the maximum overlapping between surface and water states was prevalent (Figure 11). The tailoring the donor states (conductivity), phase coexistence (solubility), heterojunctions (energetics) and surface states (kinetics) in the hematite composite photoanodes plays a decisive role in determining the PEC water oxidation performance. [117]

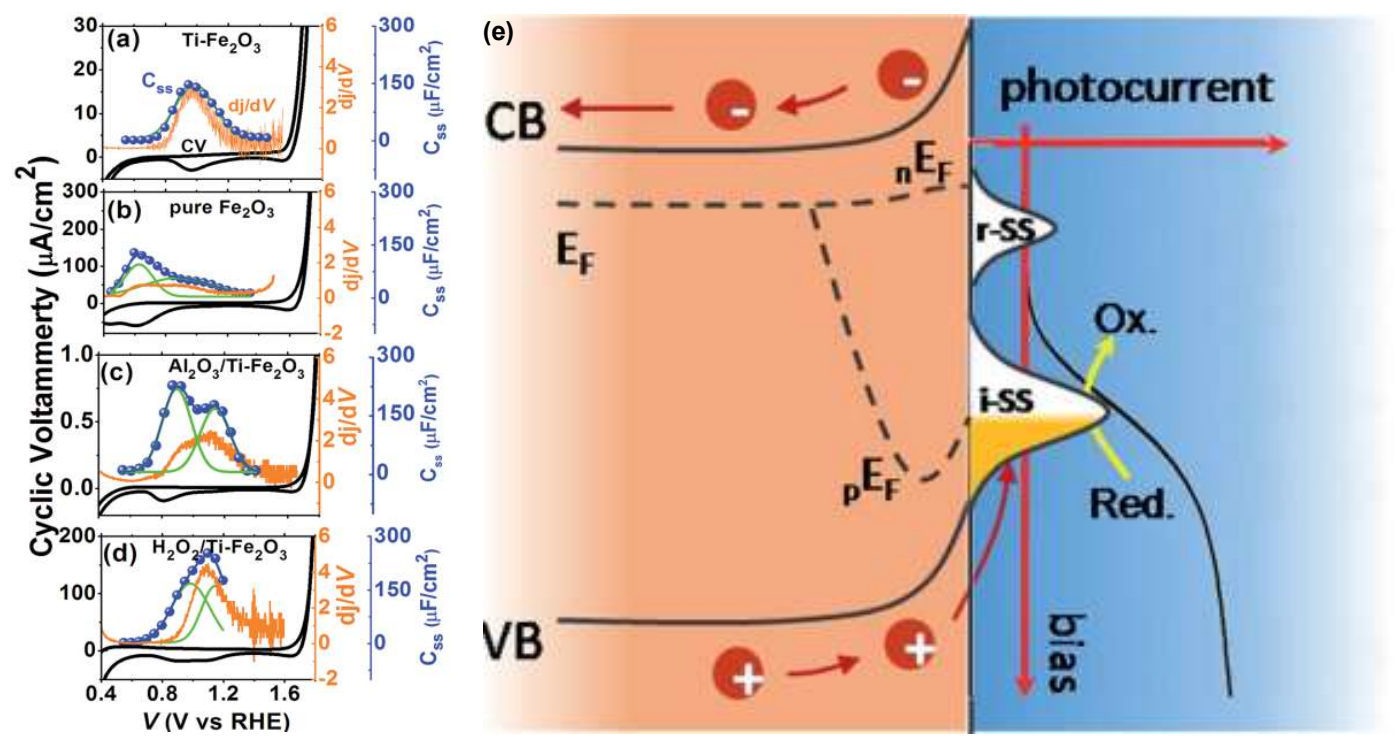

Figure 12. The relation between surface states and photocurrent based on the results of CV (black), $\mathrm{C}_{\mathrm{ss}}$ (blue) and dj/dV (orange) resulted from the electrodes of (a) $\mathrm{Ti}-\mathrm{Fe}_{2} \mathrm{O}_{3}$, (b) pure $\mathrm{Fe}_{2} \mathrm{O}_{3}$, (c) $\mathrm{Al}_{2} \mathrm{O}_{3} / \mathrm{Ti}^{-} \mathrm{Fe}_{2} \mathrm{O}_{3}$, and (d) $\mathrm{H}_{2} \mathrm{O}_{2} / \mathrm{Ti}-\mathrm{Fe}_{2} \mathrm{O}_{3}$ photoanodes. The $\mathrm{C}_{\mathrm{ss}}$ is fitted with Gauss plots (green line) and the iR-drop is compensated. (e) The schematic illustration of photo-electrochemical water oxidation on hematite photoanode with surface states as intermediates. Reproduced with permission from ref. [118] 
C. Li et al. systematically investigated the energy distribution of surface states $\left(\mathrm{C}_{\mathrm{ss}}\right)$ and dj/dV on pure $\mathrm{Fe}_{2} \mathrm{O}_{3}$, Ti- $\mathrm{Fe}_{2} \mathrm{O}_{3}, \mathrm{Al}_{2} \mathrm{O}_{3} / \mathrm{Ti}-\mathrm{Fe}_{2} \mathrm{O}_{3}$ and $\mathrm{H}_{2} \mathrm{O}_{2} / \mathrm{Ti}-\mathrm{Fe}_{2} \mathrm{O}_{3}$ electrodes. [118] As displayed in Figure 12, there is only one surface state present at the pure $\mathrm{Fe}_{2} \mathrm{O}_{3}$, Ti$\mathrm{Fe}_{2} \mathrm{O}_{3}$ and $\mathrm{H}_{2} \mathrm{O}_{2} / \mathrm{Ti}_{-}-\mathrm{Fe}_{2} \mathrm{O}_{3}$, whereas, there are two kinds of surface states appearing at the $\mathrm{Al}_{2} \mathrm{O}_{3} / \mathrm{Ti}-\mathrm{Fe}_{2} \mathrm{O}_{3}$ electrode; additionally, compared to the energy levels of the surface state peaks in pure $\mathrm{Fe}_{2} \mathrm{O}_{3}$, those of Ti- $\mathrm{Fe}_{2} \mathrm{O}_{3}, \mathrm{Al}_{2} \mathrm{O}_{3} / \mathrm{Ti}^{-} \mathrm{Fe}_{2} \mathrm{O}_{3}$ and $\mathrm{H}_{2} \mathrm{O}_{2} / \mathrm{Ti}^{-}-\mathrm{Fe}_{2} \mathrm{O}_{3}$ have been shifted close to the valence band edge. [118] Therefore, these results reveal that surface Ti modification ( $\mathrm{Ti}-\mathrm{Fe}_{2} \mathrm{O}_{3}$ electrode), $\mathrm{Al}_{2} \mathrm{O}_{3}$ coating by $\mathrm{ALD}\left(\mathrm{Al}_{2} \mathrm{O}_{3} / \mathrm{Ti}_{-}-\mathrm{Fe}_{2} \mathrm{O}_{3}\right.$ electrode), $\mathrm{H}_{2} \mathrm{O}_{2}$ treatment $\left(\mathrm{H}_{2} \mathrm{O}_{2} / \mathrm{Ti}-\mathrm{Fe}_{2} \mathrm{O}_{3}\right.$ electrode $)$ indeed modify the energy levels and density of the surface states and the corresponding PEC water splitting performance of hematite based photoanodes. B. X. Zhou et al. investigations revealed that the coating of $\mathrm{ZnFe}_{2} \mathrm{O}_{4}$ and $\mathrm{ZnO}$ layers onto hematite modified the surface sates of hematite and thus affected its PEC performance. [126] C. M. Li et al. employed a co-doping method by sequential in-situ Ti-doping and ex-situ Mg-doping in order to tailor the surface states of hematite photoanodes for great improvement of the charge transfer at the interface and the followed transport ability by the suppressed charge recombination. This resulted into about 11-folds higher than that of the undoped $\mathrm{Fe}_{2} \mathrm{O}_{3}$ at $1.23 \mathrm{~V}$ vs. $\mathrm{RHE}$, respectively. This was mainly due to $\mathrm{Mg}$ and Ti-doping into $\mathrm{Fe}_{2} \mathrm{O}_{3}$ modifying the surface states enabling more holes participation in water oxidation and better kinetics that enhanced charge transfer and suppressed charge recombination for the efficient water oxidation. [121] Additionally, T. A. Kandiel et al. reported that Ba- and Srmodified hematite photoanodes exhibited higher density of surface states and higher charge transfer rate constants at low bias potential than those of bare hematite, which might be the reason for the higher photocurrent observed for Ba- and Sr-modified hematite photoanodes. [128]

\subsubsection{Oxygen Evolution Catalyst (OEC) Overlayer Deposition}

The deposition of oxygen evolution catalysts (OEC) onto the hematite photoanodes would alter the surface states and thus enhance the PEC performance of hematite photoanodes. [129-139] For instance, G. A. Ozin et al. demonstrated that for the case of hematite/iridium catalyst composite photoanodes, the iridium catalyst not only improved the kinetics of the water oxidation reaction in both in the dark and under illumination, but also increased the density of photoholes at the surface and decreased the rate of recombination of majority charge carriers with these surface-bound charges 
at moderate to high applied potentials. [129] A. B. F. Martinson et al. reported that hematite photoanodes coated with an ultrathin $\mathrm{Co}(\mathrm{OH})_{2} / \mathrm{Co}_{3} \mathrm{O}_{4}$ layer by atomic layer deposition (ALD) resulted in significantly enhanced photoelectrochemical water oxidation performance. The enhanced PEC performance (100-200 $\mathrm{mV}$ cathodic shifts in the photocurrent onset potential, $0.81 \mathrm{~mA} / \mathrm{cm}^{-2}$ photocurrent responses at $1.23 \mathrm{~V}$ vs RHE.) is attributed to modified surface states which enable faster charge transfer from the surface states of $\mathrm{Co}(\mathrm{II}) / \mathrm{Co}_{3} \mathrm{O}_{4}$-modified hematite photoanodes than the charge transfer from the surface states of bare hematite electrodes.[130] It was reported by $\mathrm{T}$. W. Hamann and D. R. Gamelin et al. that the deposition of Cobalt phosphate (Co- $\left.\mathrm{P}_{\mathrm{i}}\right)$ onto the hematite photoanodes surface changes the nature of the surface states in

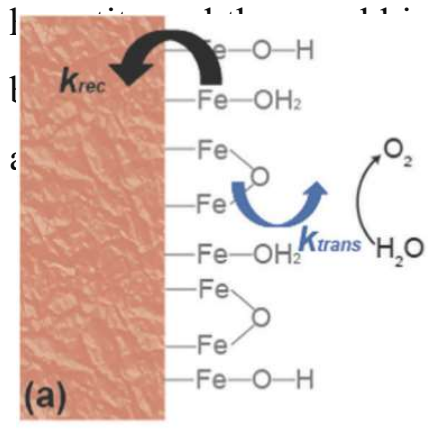

(a)

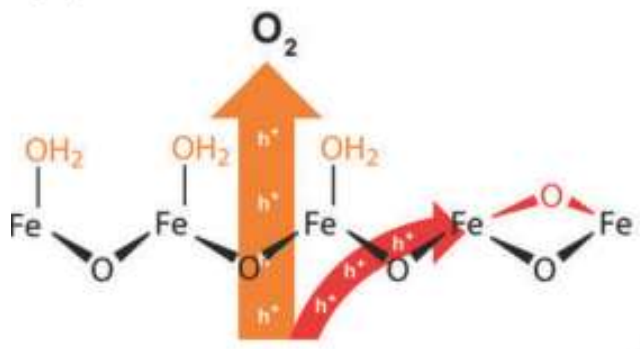

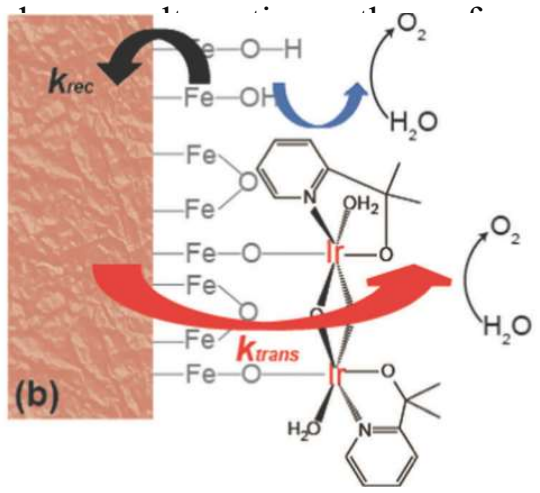

(b)
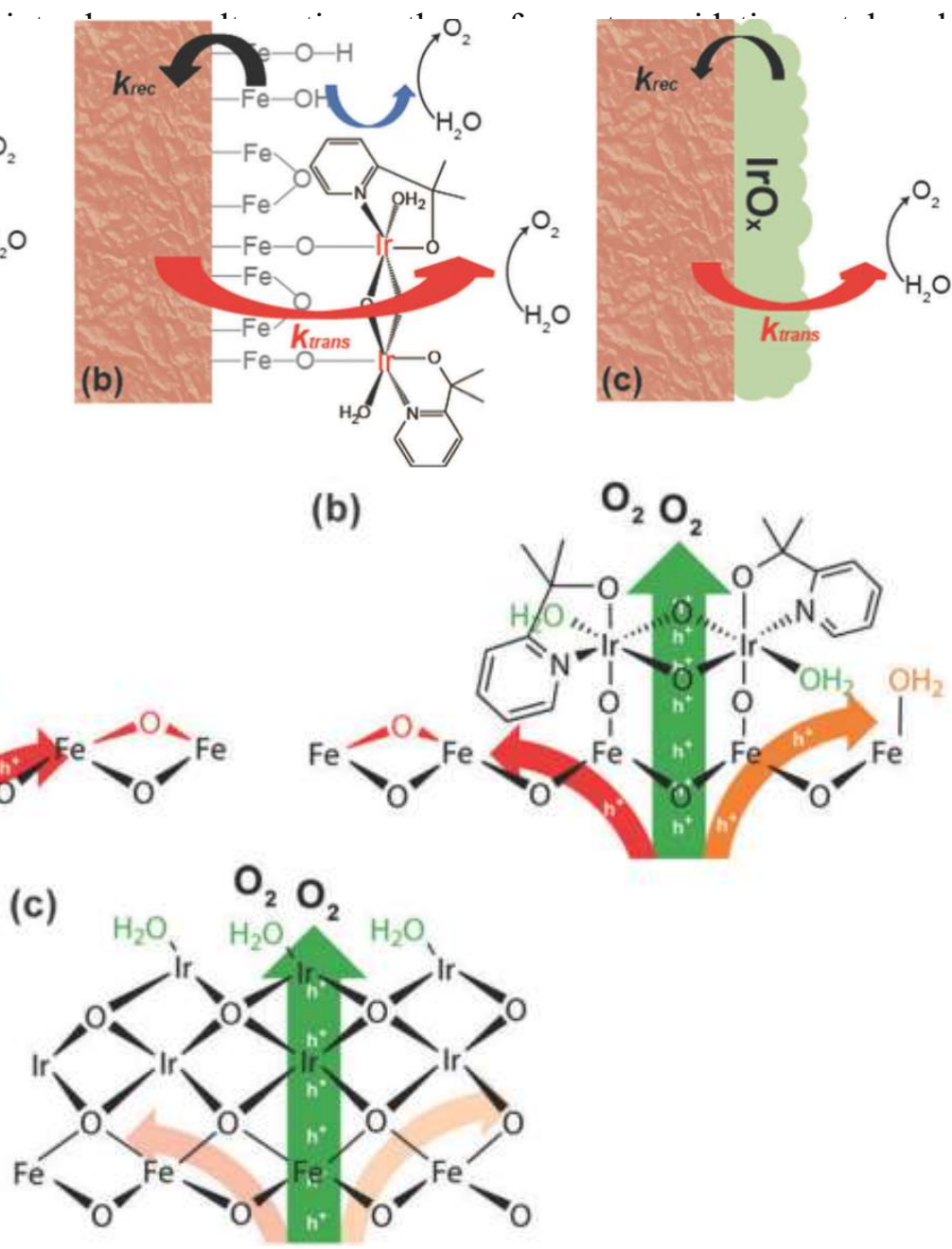
Figure 13. Top: Schematic illustrations of the kinetic models for (a) bare hematite (b) hematite with hetWOC and (c) hematite with $\mathrm{IrO}_{x}$. Bottom: Mechanistic perspective of bare hematite (a), hematite with het-WOC (b) and hematite with $\mathrm{IrO}_{\mathrm{x}}(\mathrm{c})$. Reproduced with permission from ref. [134]

Meanwhile, D. W. Wang et al. reported that when a thin layer of a heterogenized molecular Ir catalyst (het-WOC) is applied to a hematite photoanode, the photocurrent response is improved from ca. $0.25 \mathrm{~mA} / \mathrm{cm}^{-2}$ to $0.66 \mathrm{~mA} / \mathrm{cm}^{-2}$ at $1.23 \mathrm{~V}$ vs RHE in acidic electrolyte. [133] The detailed mechanism investigation about the system via PEIS and IMPS reveals that the enhanced PEC performance is primarily due to the improved charge transfer (42 fold), while the surface recombination rate remains unchanged. In stark contrast, heterogeneous oxide catalysts $\left(\mathrm{IrO}_{\mathrm{x}}\right)$ coating improve the PEC performance of hematite by significantly reducing the surface recombination rate. These results suggest that the het-WOC provides additional charge-transfer pathways across the $\mathrm{Fe}_{2} \mathrm{O}_{3} \mid \mathrm{H}_{2} \mathrm{O}$ interface, while $\mathrm{IrO}_{\mathrm{x}}$ and similar bulk metal-oxide catalysts replace the $\mathrm{Fe}_{2} \mathrm{O}_{3} \mid \mathrm{H}_{2} \mathrm{O}$ interface with a fundamentally different one, as displayed in Figure 13. [134] Recently, S. Eslava et al. unravelled the nature of the interactions between different loadings of an electrocatalyst $\left(\mathrm{CoFeO}_{\mathrm{x}}\right)$ and a hematite semiconductor via a combination of electrochemical approaches of PEIS and IMPS. They found that a thin layer $\mathrm{CoFeO}_{\mathrm{x}}$ mainly reduces surface charge recombination, while an extremely thin layer $\mathrm{CoFeO}_{\mathrm{x}}$ enhances charge transfer kinetics; an interlayer of $\mathrm{GaO}_{\mathrm{x}}$ modifies the surface state distribution and increases the charge transfer rate. [137]

\subsubsection{Doping, Secondary Semiconductors and OEC Overlayers}

Other researchers are devoted to the combination of secondary semiconductors and OEC overlayers to modifying donor density and the surface states of hematite photoanodes for further enhancing PEC performance of hematite-based photoanodes. $[14,120,125,140]$ X. L. Zheng et al. reported a facile and rapid three-step approach to simultaneously reduce the bulk, interface, and surface recombinations for the hematite nanorod array based photoanode, leading to a greatly improved photocurrent density at low bias potential. [140] In this strategy, flame-doping enhance the Ti doping concentration without hampering the morphology and surface properties of the hematite nanorods, which effectively reduces both the bulk and surface recombinations. Then, the addition of a dense-layer between the hematite nanorods and the FTO glass substrate reduces the interfacial recombination by suppressing the electron back-injection into the electrolyte. Finally, the sequential oxalic acid etching and $\mathrm{FeOOH}$ deposition improves 
both the interface quality between $\mathrm{FeOOH}$ electrocatalyst and the hematite nanorods and the surface catalytic activity. [140]
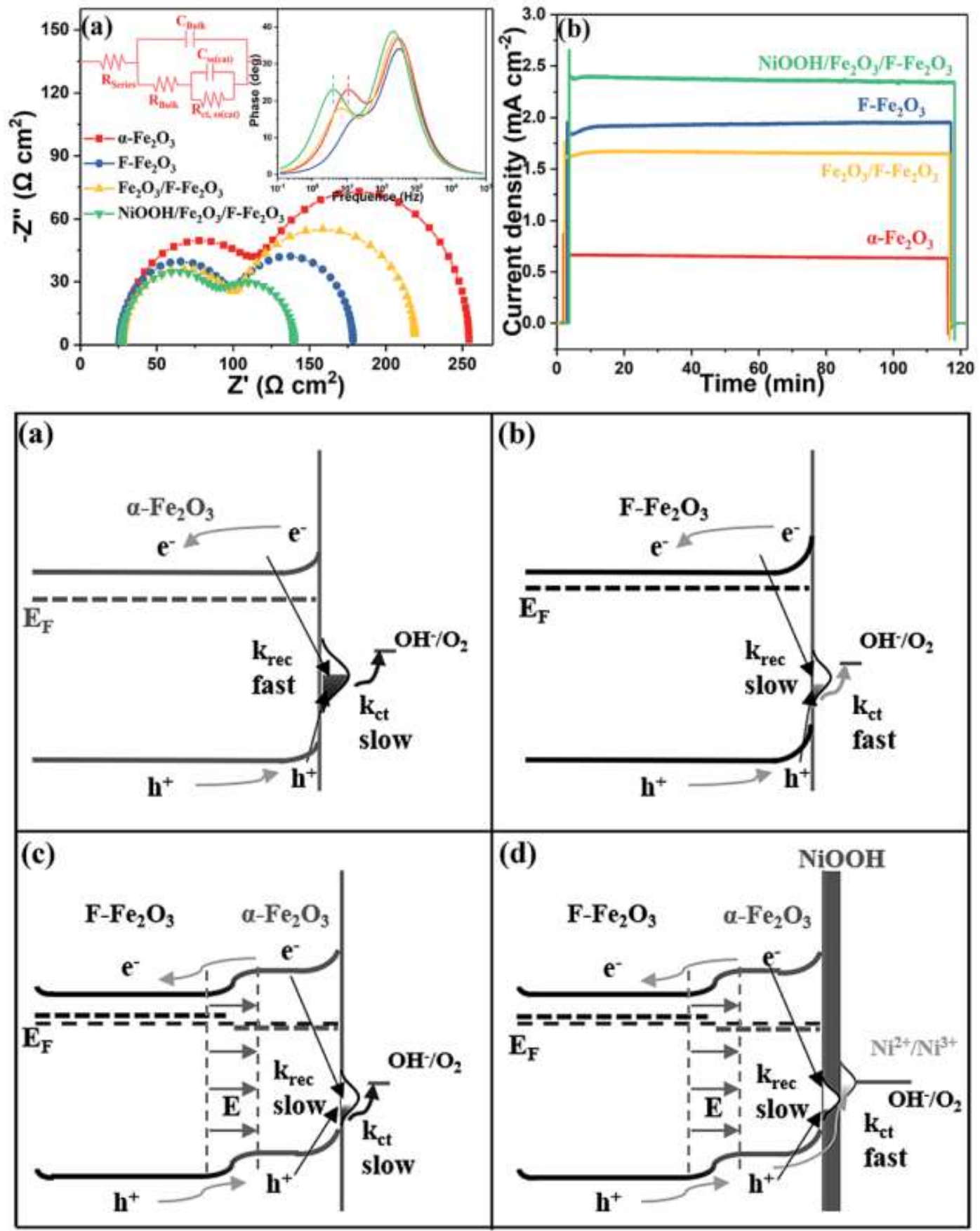

Figure 14. Top: (a) Nyquist plots of the samples at $1.05 \mathrm{~V}$ vs. RHE under illumination and (b) chronoamperometry of all photoanodes in a period of $2 \mathrm{~h}$. Bottom: Energetic schemes for (a) $\mathrm{Fe}_{2} \mathrm{O}_{3}$, (b) F- $\mathrm{Fe}_{2} \mathrm{O}_{3}$, (c) $\mathrm{Fe}_{2} \mathrm{O}_{3} / \mathrm{F}_{-} \mathrm{Fe}_{2} \mathrm{O}_{3} \mathrm{NRs}$ and (d) $\mathrm{NiOOH} / \mathrm{Fe}_{2} \mathrm{O}_{3} / \mathrm{F}-\mathrm{Fe}_{2} \mathrm{O}_{3}$ photoanode, where krec refer to the surface recombination and kct represent charge transfer through surface states. Reproduced with permission from ref. [125] 
Meanwhile, J. T. Ma et al. fabricated a NiO/P-Fe $2 \mathrm{O}_{3}$ composite photoanode which produced a high photocurrent density of $2.08 \mathrm{mAcm}^{-2}$ at $1.23 \mathrm{~V}$ vs RHE and a $110 \mathrm{mV}$ cathodic shift of the onset potential, which was ascribed to the improved electrical conductivity and the modified surface states because of the $\mathrm{P}$ doping and $\mathrm{NiO}$ coating. [120] Moreover, J.T. Ma et al. further demonstrated that F-doping and NiOOH coating onto hematite photoanodes resulted in enhanced PEC water splitting performance, fulfilling the requirements of low surface trapping sites, high conductivity, efficient charge separation and injection efficiency, as shown in Figure 14. [125]

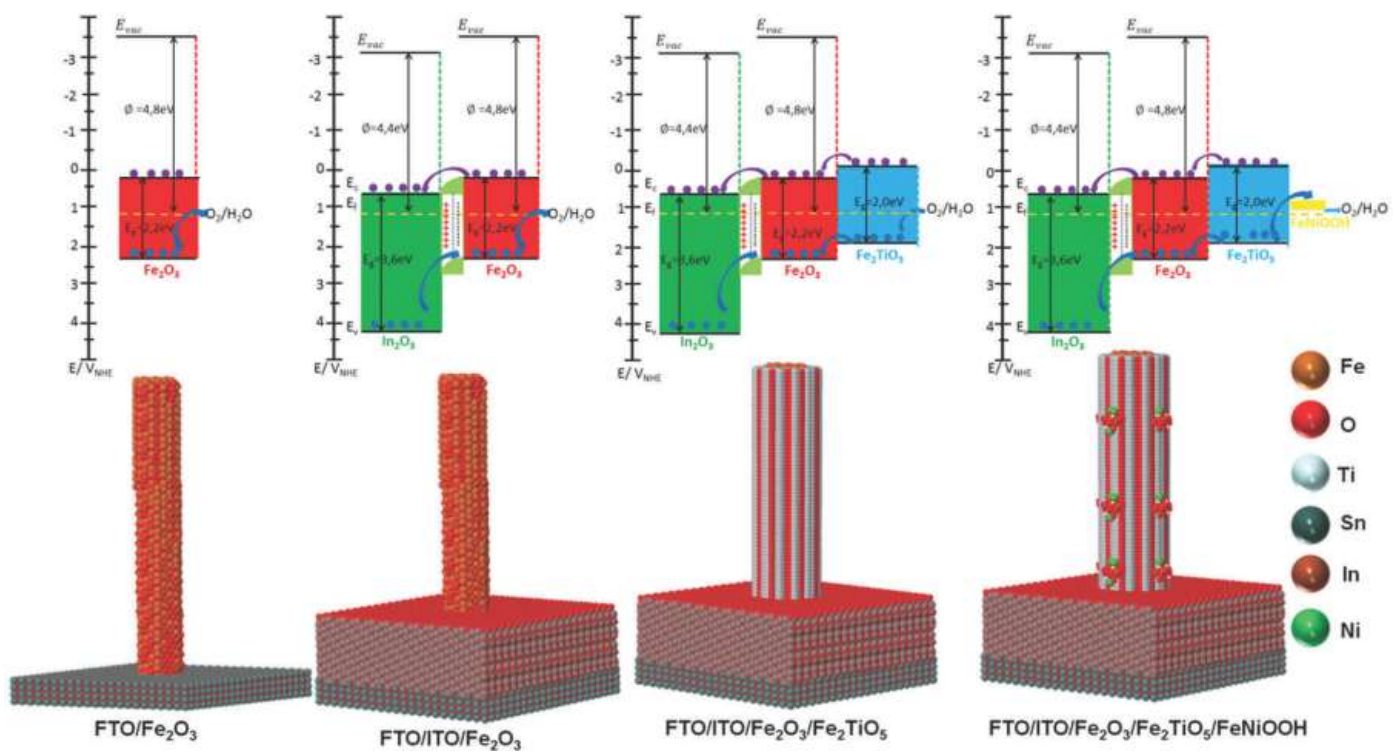

Figure 15. Top: Thermodynamic scheme for the charge transfer processes at $1.23 \mathrm{~V}$ vs. RHE of SEI under illumination for the $\mathrm{Fe}_{2} \mathrm{O}_{3}$, ITO/ $/ \mathrm{Fe}_{2} \mathrm{O}_{3}, \mathrm{ITO} / \mathrm{Fe}_{2} \mathrm{O}_{3} / \mathrm{Fe}_{2} \mathrm{TiO}_{5}$, and $\mathrm{ITO} / \mathrm{Fe}_{2} \mathrm{O}_{3} / \mathrm{Fe}_{2} \mathrm{TiO}_{5} / \mathrm{FeNiOOH}$ electrodes. The black arrows indicate the bandgap of $\mathrm{In}_{2} \mathrm{O}_{3}$ (ITO matrix), hematite and $\mathrm{Fe}_{2} \mathrm{TiO}_{5}$. The dark blue arrow refers to the hole transfer process at the heterojunction interfaces. The purple arrow refers to the electron transfer process present at the heterojunction interfaces. For simplicity, interfacial charge transfer is considered to occur through the $\mathrm{E}_{\mathrm{V}}$ and/or $\mathrm{E}_{\mathrm{C}}$ states directly, without the intervention of interfacial SS. In all photoanodes, 4 electron-hole couples per visible active semiconductor are depicted. $\mathrm{In}_{2} \mathrm{O}_{3}$ (main ingredient of ITO matrix): green; $\mathrm{Fe}_{2} \mathrm{O}_{3}$ : red; $\mathrm{Fe}_{2} \mathrm{TiO}_{5}$ : indigo; FeNiOOH: yellow. Bottom: The atomic supercell models illustrate the interfaces existing at $\mathrm{In}_{2} \mathrm{O}_{3}$ (ITO matrix), hematite, $\mathrm{Fe}_{2} \mathrm{TiO}_{5}$ and FeNiOOH species in the integrated electrodes. Reproduced with permission from ref. [14]

Recently, we have reported that the fabrication of ITO/ $\mathrm{Fe}_{2} \mathrm{O}_{3} / \mathrm{Fe}_{2} \mathrm{TiO}_{5} / \mathrm{FeNiOOH}$ multilayer nanowires (Figure 15) for PEC water splitting and elucidated the mechanism underlying the interfacial coupling effect of the quaternary hematite composite photoanode. [14] In this work, secondary semiconductors (ITO, $\left.\mathrm{Fe}_{2} \mathrm{TiO}_{5}\right)$ and $\mathrm{OECs}$ were combined to modify the donor density and surface states in the composite photoanodes, delivering $2.2 \mathrm{~mA} \mathrm{~cm}^{-2}$ at $1.23 \mathrm{~V}$ vs RHE and 1 sun, which is 10 times higher than that of pristine hematite photoanodes. A deep and careful investigation into the mechanism responsible for the enhanced PEC performance of ITO/ $/ \mathrm{Fe}_{2} \mathrm{O}_{3} / \mathrm{Fe}_{2} \mathrm{TiO}_{5} /$ 
FeNiOOH multi-layer nanowires show that: (i) the ITO underlayer is used as a high quality electrical back contact to reduce the back-contact interface charge recombination and as a Sn doping source for tuning the donor density, (ii) the atomic level $\mathrm{Fe}_{2} \mathrm{TiO}_{5}$ coating, serves as the surface states density and energy level modulation layer, effectively suppresses the charge recombination at the semiconductor junction interface, (iii) the FeNiOOH nanodots, increase the surface active sites, and thus accelerates the OER kinetics at the SEI. The interfacial coupling effect between the ITO underlayer, the ultrathin $\mathrm{Fe}_{2} \mathrm{TiO}_{5}$ and the $\mathrm{FeNiOOH}$ nanodots in the $\mathrm{ITO} / \mathrm{Fe}_{2} \mathrm{O}_{3} / \mathrm{Fe}_{2} \mathrm{TiO}_{5} / \mathrm{FeNiOOH}$ photoanodes simultaneously enhances the charge separation and water oxidation efficiency. [14] Most recently, we integrated $\mathrm{Fe}_{2} \mathrm{O}_{3}$ nanowires with an ultrathin $\mathrm{Fe}_{2} \mathrm{TiO}_{5}$ heterojunction and CoFe-Prussian blue analogue (PBA) decoration for enhanced PEC water splitting in acid electrolyte $(\mathrm{pH}=1)$. Thanks to the combination of core-shell $\mathrm{Fe}_{2} \mathrm{O}_{3} / \mathrm{Fe}_{2} \mathrm{TiO}_{5}$ type II heterojunction nanowires and the catalytic function of CoFe-PBA, $\mathrm{Fe}_{2} \mathrm{O}_{3} / \mathrm{Fe}_{2} \mathrm{TiO}_{5} / \mathrm{CoFe}-\mathrm{PBA}$ composite photoanodes are able to deliver $1.25 \mathrm{~mA} \mathrm{~cm}{ }^{-2}$ photocurrent at $1.23 \mathrm{~V}$ vs. RHE, almost one order of magnitude photocurrent increment in comparison to the pristine $\mathrm{Fe}_{2} \mathrm{O}_{3}$ nanowires. Systematic electrochemical investigation reveals that the enhanced PEC performance of the $\mathrm{Fe}_{2} \mathrm{O}_{3} / \mathrm{Fe}_{2} \mathrm{TiO}_{5} / \mathrm{CoFe}-\mathrm{PBA}$ composite electrode can be attributed to the modified surface states density after successive coatings. [141]

\section{Conclusions and prospects}

An earth abundant nature and excellent visible-light response endow hematite based photoanodes with promising photoelectrochemical water oxidation activity in the fields of PEC water splitting. Studies centred on the hematite based photoanodes will be beneficial for the future development of other photoelectrodes. Considerable work has been performed to control the composition, morphology, and nanostructure of hematite based photoanodes to improve its PEC water splitting performance. Although significant progress has been achieved, great efforts are still required to further explore the surface states mediated charge transfer mechanism of hematite based photoanodes for PEC water oxidation. In this review, we have summarized the recent progresses on hematite photoanodes for PEC water splitting and highlighted the critical role of surface sates in the development of high-performance hematite based photoanodes for the PEC water splitting application. As a model system, the approach summarized here of hematite composite photoanodes might also be employed for the investigation of other surface sates mediated photoelectrodes for PEC water splitting, 
including $\mathrm{TiO}_{2}, \mathrm{BiVO}_{4}, \mathrm{CuWO}_{4}, \mathrm{GaN}, \mathrm{CuFeO}_{2}, \mathrm{Ta}_{3} \mathrm{~N}_{5}, \mathrm{Cu}(\mathrm{In}, \mathrm{Ga})(\mathrm{Se}, \mathrm{S})_{2}$. [41-48, 98, 142-143] The following three aspects deserve special attention in the future investigation of hematite based photoanodes system in order to definitely improve their PEC efficiency:

(1) Typically, the previous investigation attributed the enhanced PEC water splitting performance of hematite composite photoanodes either to the improved donor density or the changed surface states. Indeed, it is essential to simultaneously monitor the evolution of the donor density and surface states of hematite based photoanodes upon doping, type II heterojunction construction and OEC deposition.

(2) Previous studies on hematite based photoanodes have mainly focused on the strategy for the improvement of the PEC water oxidation performance via the design of nanostructures, doping, heterojunction and OEC deposition. Few studies have reported the investigation about the mechanisms that are responsible for the enhanced PEC performance. Several previous mechanism investigations have been focused on simple hematite based photoanode systems. However, the main obstacle is to correlate the charge transfer efficiency at the SEI with the surface states evolution upon the coating of a secondary semiconductor or OEC. More hematite based composite photoanode systems should be extensively explored to overcome these obstacles.

(3) Most of the designing of composite hematite based photoanodes are limited to pristine or binary systems rather than ternary or quaternary composite photoelectrode systems. The integration of ternary or quaternary composite photoelectrodes with a secondary underlayer, overlayer and $\mathrm{OEC}$ is favourable for the improvement of the hematitebased photoanodes because the charge recombination simultaneously occurs at the multiinterfaces, including the back contact, bulk interfaces and SEI interfaces. Therefore, extending exploration of more complex hematite-based photoanodes might be of high interest.

(4) Various techniques have been employed to probe the nature of the surface states in hematite-based photoanode systems, including PEIS, CV, IMPS, IMVS, DRT, in-situ UVvis, in-situ ATR-IR, 4D TEM, DFT, SECM and KIE. Nevertheless, the accurate observation of surface states/surface intermediates at hematite photoanodes with spatial, temporal and energy resolution is still limited. Further deep investigations about the PEC water oxidation in hematite photoanodes will require emerging in-situ techniques, like atomic force microscope,[144] single-molecule super-resolution fluorescence microscopy,[78, 145] insitu (S)TEM, [146] surface photovoltage microscopy (SPVM), [147], on-line inductively 
coupled plasma mass spectrometer (ICP-MS),[148] and dual-working-electrode photoelectrochemistry techniques.[149-151]

\section{Acknowledgements}

Authors acknowledge funding from Generalitat de Catalunya 2017 SGR 327, the Spanish MINECO project ENE2017-85087-C3 and the BIST Ignite project InWOC2. ICN2 is supported by the Severo Ochoa program from Spanish MINECO (Grant No. SEV-20170706) and is funded by the CERCA Programme / Generalitat de Catalunya. Part of the present work has been performed in the framework of Universitat Autònoma de Barcelona Materials Science $\mathrm{PhD}$ program.

\section{References:}

[1] P. Zhang, T. Wang, J. L. Gong, Current mechanistic understanding of surface reactions over water-splitting photocatalysts, Chem, 2017, 4, 223-245.

[2] G. Chen, J. Seo, C. Yang, P. N. Prasad, Nanochemistry and nanomaterials for photovoltaics, Chem. Soc. Rev. 2013, 42, 8304-8338.

[3] M. G. Walter, E. L. Warren, J. R. McKone, S. W. Boettcher, Q. Mi, E. A. Santori, N. S. Lewis, Solar water splitting cells, Chem. Rev. 2010,110, 6446-6473.

[4] N. S. Lewis, D. G. Nocera, Powering the planet: chemical challenges in solar energy utilization, Proc. Natl. Acad. Sci. USA, 2006, 103, 15729-15735.

[5] X. Chen, S. Shen, L. Guo, S.S. Mao, Semiconductor-based photocatalytic hydrogen generation, Chem. Rev. 2010, $110,6503-6570$

[6] F. Urbain, P. Y. Tang, N. M. Carretero, T. Andreu, L. G. Gerling, C. Voz, J. Arbiol, J. R. Morante, Energy Environ. Sci., 2017, 10, 2256-2266.

[7] A. Fujishima, K. Honda, Electrochemical photolysis of water at a semiconductor electrode, Nature, 1972, 238, 37-38.

[8] A. J. Bard, M. A. Fox, Artificial photosynthesis: solar splitting of water to hydrogen and oxygen. Acc. Chem. Res., 1995, 28, 141-145.

[9] N. S. Lewis, Toward cost-effective solar energy use, Science, 2007, 315, 798-801.

[10] K. Sivula, R. V. D. Krol. Semiconducting materials for photoelectrochemical energy conversion, Nature Rev. Mater., 2016, 1, 15010.

[11] S. H. Shen, S. A. Lindley, X. Y. Chen, J. Z. Zhang, Hematite heterostructures for photoelectrochemical water splitting: rational materials design and charge carrier dynamics, Energy Environ. Sci., 2016, 9, 2744-2775.

[12] Z. Q. Huang, Y. J. Lin, X. Xiang, W. Rodríguez-Córdoba, K. J. McDonald, K. S. Hagen, K. S. Choi, B. S. Brunschwig, D. G. Musaev, C. L. Hill, D. W. Wang, T. Q. Lian, In situ probe of photocarrier dynamics in watersplitting hematite $\left(\alpha-\mathrm{Fe}_{2} \mathrm{O}_{3}\right)$ electrodes, Energy Environ. Sci., 2012, 5, 8923-8926.

[13] S. R. Pendlebury, A. J. Cowan, M. Barroso, K. Sivula, J. H. Ye, M. Grätzel, D. R. Klug, J. W. Tang, J. R. Durrant, Correlating long-lived photogenerated hole populations with photocurrent densities in hematite water oxidation photoanodes, Energy Environ. Sci., 2012, 5, 6304-6312.

[14] P. Y. Tang, H. B. Xie, C. Ros, L. J. Han, M. Biset-Peiró, Y. M. He, W. Kramer, A. Perez-Rodriguez, E. Saucedo, J. Galan-Mascaros, T. Andreu, J. R. Morante, J. Arbiol, Enhanced photoelectrochemical water splitting of hematite multilayer nanowires photoanode with tuning surface state via bottom-up interfacial engineering, Energy Environ. Sci., 2017, 10, 2124-2136.

[15] A. G. Tamirat, J. Rick, A. A. Dubale, W. N. Su, B. J. Hwang, Using hematite for photoelectrochemical water splitting: a review of current progress and challenges, Nanoscale Horiz., 2016, 1, 243-267.

[16] M.Y. Li, Y.Y. Qiu, W.T. Qiu, S.T. Tang, S. Xiao, S.L. Ma, G.F. Ouyang, Y.X. Tong, S.H. Yang, Boosting the photoelectrochemical water oxidation at hematite photoanode by innovating a hierarchical ball-on-wire-array, $A C S$ Appl. Energy Mater. 2018, 1, 5836-5841.

[17] L. Wang, N. T. Nguyen, Z. Q. Shen, P. Schmuki, Y. P. Bi, Hematite dodecahedron crystals with high-index facets grown and grafted on one dimensional structures for efficient photoelectrochemical $\mathrm{H}_{2}$ generation, Nano Energy, 2018, 50, 331-338.

[18] H. M. Zhang,Y. K. Kim, H. Y. Jeong, J. S. Lee, A few atomic $\mathrm{FeNbO}_{4}$ overlayers on hematite nanorods: Microwave-induced high temperature phase for efficient photoelectrochemical water splitting, ACS Catal. 2019, 9 , 1289-1297.

[19] A. Annamalai, P. S. Shinde, A. Subramanian, J. Y. Kim, J. H. Kim, S. H. Choi, J. S. Lee, J. S. Jang, Bifunctional 
$\mathrm{TiO}_{2}$ underlayer for a- $\mathrm{Fe}_{2} \mathrm{O}_{3}$ nanorod based photoelectrochemical cells: enhanced interface and $\mathrm{Ti}^{4+}$ doping, J. Mater. Chem. A, 2015, 3, 5007-5013.

[20] P. Zhang, L. Yu, X. W. Lou, Construction of heterostructured $\mathrm{Fe}_{2} \mathrm{O}_{3}-\mathrm{TiO}_{2}$ microdumbbells for photoelectrochemical water oxidation, Angew. Chem. 2018, 130, 15296-15300.

[21] Z.B. Luo, T. Wang, J.J. Zhang, C.C. Li, H.M. Li, J.L. Gong, Dendritic hematite nanoarray photoanode modified with a conformal titanium dioxide interlayer for effective charge collection, Angew. Chem. Int. Ed. 2017, 56, 12878 12882.

[22] A. Tsyganok, D. Klotz, K. D. Malviya, A. Rothschild, D. A. Grave, Different roles of $\mathrm{Fe}_{1-\mathrm{x}} \mathrm{Ni}_{\mathrm{x}} \mathrm{OOH}$ cocatalyst on hematite $\left(\alpha-\mathrm{Fe}_{2} \mathrm{O}_{3}\right)$ photoanodes with different dopants, ACS Catal. 2018, 8, 2754-2759.

[23] B. Eftekharinia, A. Moshaii, N. S. Vayghan, A. Dabirian, Efficient nanoporous hematite photoanodes prepared by electron beam evaporation and Au modification, ChemCatChem, 2018, 10, 4665-4675.

[24] J. J. Deng, Q. Z. Zhang, K. Feng, H. W. Lan, J. Zhong, M. Chaker, D. L. Ma, ChemSusChem, 2018, 11, $3783-$ 3789 .

[25] S. H. Shen, S. A. Lindley, C. L. Dong, E.F. Chen, Y. R. Lu, J. G. Zhou, Y. F. Hu, D. A. Wheeler, P. H. Guo, J. Z. Zhang, D. S. Kliger, S. S. Mao, Sol. RRL, 2019, 3, 1800285.

[26] S. S. Yi, B. R. Wulan, J. M. Yan, Q. Jiang, Highly efficient photoelectrochemical water splitting: Surface modification of cobalt-phosphate-loaded $\mathrm{Co}_{3} \mathrm{O}_{4} / \mathrm{Fe}_{2} \mathrm{O}_{3}$ p-n heterojunction nanorod arrays, Adv. Funct. Mater. 2019, 29, 1801902.

[27] Y. Choi, D. Jeon, Y. Choi, D. Kim, N. Kim, M.S. Gu, S. Bae, T. Lee, H.W. Lee, B. S. Kim, J. Ryu, Interface engineering of hematite with nacre-like catalytic multilayers for solar water oxidation, ACS Nano, 2019, 13, 467-475.

[28] J. J. Zhao, Y. H. Li, P. F. Liu, Y. L. Wang, X. L. Du, X. L. Wang, H. D. Zeng, L. R. Zheng, H. G. Yang, Local coulomb attraction for enhanced $\mathrm{H}_{2}$ evolution stability of metal sulfide photocatalysts, Applied Catalysis B: Environmental, 2018, 221, 152-157.

[29] S. M. Ho-Kimura, B. A. D. Williamson, S. Sathasivam, S. J. A. Moniz, G. J. He, W. J. Luo, D. O. Scanlon, J. W. Tang, I. P. Parkin, ACS Omega, 2019, 4, 1449-1459.

[30] J. J. Deng, X. X. Lv, J. Zhong, Photocharged $\mathrm{Fe}_{2} \mathrm{TiO}_{5} / \mathrm{Fe}_{2} \mathrm{O}_{3}$ photoanode for enhanced photoelectrochemical water oxidation, J. Phys. Chem. C, 2018, 122, 29268-29273.

[31] P. Peerakiatkhajohn, J. H. Yun, H. J. Chen, M. Q. Lyu, T. Butburee, L. Z. Wang, Adv. Mater. 2016, 28, 64056410.

[32] C.C. Li, A. Li, Z. B. Luo, J. J. Zhang, X. X. Chang, Z. Q. Huang, T. Wang, J. L. Gong, Surviving hightemperature calcination: $\mathrm{ZrO}_{2}$-induced hematite nanotubes for photoelectrochemical water oxidation, Angew. Chem. Int. Ed. 2017, 56, 4150-4155.

[33] M. P. Cardona, M.Y. Li, W. Li, J McCall, D. W. Wang, Y. Li, C. Yang, The role of graphene as an overlayer on nanostructured hematite photoanodes for improved solar water oxidation, Materials Today Energy, 2018, 8, 8-14.

[34] H. M. Zhang, W. Y. Noh, F. Li, J. H. Kim, H. Y. Jeong, J. S. Lee, Three birds, one-stone strategy for hybrid microwave synthesis of $\mathrm{Ta}$ and $\mathrm{Sn}$ codoped $\mathrm{Fe}_{2} \mathrm{O}_{3} @ \mathrm{FeTaO}_{4}$ nanorods for photo-electrochemical water oxidation, $A d v$. Funct. Mater. 2019, 29, 1805737.

[35] H. Lin, X. Long, Y. M. An, D. Zhou, S. H. Yang, Three-dimensional decoupling Co-catalyst from a photoabsorbing semiconductor as a new strategy to boost photoelectrochemical water splitting, Nano Lett. 2019, 19, 455-460.

[36] S. D. Tilley, M. Cornuz, K. Sivula, M. Grätzel, Light-induced water splitting with hematite: Improved nanostructure and iridium oxide catalysis, Angewandte Chemie International Edition, 2010, 49, 6405-6408.

[37] F. L. Formal, N. Tétreault, M. Cornuz, T. Moehl, M. Grätzel, K. Sivula, Passivating surface states on water splitting hematite photoanodes with alumina overlayers, Chem. Sci., 2011, 2, 737-743.

[38] J. A. Turner, A realizable renewable energy future, Science, 1999, 285, 687-689.

[39] J. R. Bolton, S. J. Strickler, J. S. Connolly, Limiting and realizable efficiencies of solar photolysis of water, Nature, 1985, 316, 495-500.

[40] S. Giménez, J. Bisquert, Photoelectrochemical solar fuel production from basic principles to advanced devices, Photoelectrochemical solar fuel production, 2016, Springer.

[41] J. J. Kelly, R. Memming, The influence of surface recombination and trapping on the cathodic photocurrent at ptype III-V electrodes. J. Electrochem. Soc., 1982, 129, 730-738.

[42] M.P. Dareedwards, J.B. Goodenough, A. Hamnett, P. R. Trevellick, Electrochemistry and photoelectrochemistry of Iron(III) oxide, J. Chem. Soc. Farad Trans I, 1983, 79, 2027-2041.

[43] Q. Shi, S. Murcia-López, P.Y. Tang, C. Flox, J. R. Morante, Z.Y. Bian, H. Wang, T. Andreu, Role of tungsten doping on the surface states in $\mathrm{BiVO}_{4}$ photoanodes for water oxidation: Tuning the electron trapping process, $A C S$ Catal. 2018, 8, 3331-3342.

[44] Y. Gao, T. W. Hamann, Elucidation of $\mathrm{CuWO}_{4}$ surface states during photoelectrochemical water oxidation, $J$. Phys. Chem. Lett. 2017, 8, 2700-2704.

[45] P. Varadhan, H.C. Fu, D. Priante, J. R. D. Retamal, C. Zhao, M. Ebaid, T. K. Ng, I. Ajia, S. Mitra, I. S. Roqan, B. Ooi, J.H. He, Surface passivation of GaN nanowires for enhanced photoelectrochemical water-splitting, Nano Lett, 2017, 17, 1520-1528.

[46] M. S. Prévot, X. A. Jeanbourquin, W. S. Bourée, F. Abdi, D. Friedrich, R. V. Krol, N. Guijarro, F. L. Formal, K. Sivula, Evaluating charge carrier transport and surface states in $\mathrm{CuFeO}_{2}$ photocathodes, Chem. Mater. 2017, 29 , 4952-4962.

[47] Y. M. He, J. E. Thorne, C.H. Wu, P.Y. Ma, C. Du, Q. Dong, J. H. Guo, D. W. Wang, What limits the performance of $\mathrm{Ta}_{3} \mathrm{~N}_{5}$ for solar water splitting? Chem, 2016, 1, 640-655. 
[48] S. Y. Chae, S. J. Park, S. G. Han, H. Jung, C.W. Kim, C. Jeong, O.S. Joo, B. K. Min, Y. J. Hwang, J. Am. Chem. Soc. 2016, 138, 15673-15681.

[49] P. Salvador, C. Gutierrez, The nature of surface states involved in the photo- and electroluminescence spectra of n-titanium dioxide electrodes. J. Phys. Chem., 1984, 88, 3696-3698.

[50] P. Salvador, C. Gutierrez, Mechanisms of charge transfer at the semiconductor-electrolyte interface. $J$. Electrochem. Soc., 1984, 131,326-336.

[51] L. Bertoluzzi, P. L. Varo, J. A. J. Tejada, J. Bisquert, Charge transfer processes at the semiconductor/ electrolyte interface for solar fuel production: insight from impedance spectroscopy, J. Mater. Chem. A, 2016, 4, 2873-2879.

[52] J. Bisquert, Theory of the impedance of charge transfer via surface states in dye-sensitized solar cells. $J$. Electroanal. Chem., 2010, 646, 43-51.

[53] K. G. U. Wijayantha, S. Saremi-Yarahmadi, L. M. Peter, Kinetics of oxygen evolution at $\alpha-\mathrm{Fe}_{2} \mathrm{O}_{3}$ photoanodes: a study by photoelectrochemical impedance spectroscopy, Phys. Chem. Chem. Phys., 2011, 13, 5264-5270.

[54] B. Klahr, S. Gimenez, F. Fabregat-Santiago, T. Hamann, J. Bisquert, Water oxidation at hematite photoelectrodes: The role of surface states, J. Am. Chem. Soc. 2012, 134, 4294-4302.

[55] B. Klahr, S. Gimenez, F. Fabregat-Santiago, J. Bisquert, T. W. Hamann, Electrochemical and photoelectrochemical investigation of water oxidation with hematite electrodes, Energy Environ. Sci., 2012, 5, 76267636.

[56] L. Bertoluzzi, J. Bisquert, Equivalent circuit of electrons and holes in thin semiconductor films for photoelectrochemical water splitting applications, J. Phys. Chem. Lett. 2012, 3, 2517-2522.

[57] T. Lopes, L. Andrade, F. L. Formal, M. Gratzel, K. Sivula, A. Mendes, Phys. Chem. Chem. Phys., 2014, 16, 16515-16523.

[58] O. Zandi, A. R. Schon, H. Hajibabaei, T. W. Hamann, Enhanced charge separation and collection in highperformance electrodeposited hematite films, Chem. Mater. 2016, 28, 765-771.

[59] C. Y. Cummings, F. Marken, L. M. Peter, K. G. U. Wijayantha, A. A. Tahir, New Insights into Water Splitting at Mesoporous $\alpha-\mathrm{Fe}_{2} \mathrm{O}_{3}$ Films: A Study by Modulated Transmittance and Impedance Spectroscopies, J. Am. Chem. Soc., 2011, 134, 1228-1234.

[60] J. Reichman, The current-voltage characteristics of semiconductor-electrolyte junction photovoltaic cells, Appl. Phys. Lett. 1980, 36, 574-577.

[61] J. Bisquert, Theory of the impedance of charge transfer via surface states in dye-sensitized solar cells, $J$. Electroanal. Chem. 2010, 646, 43-51.

[62] E. A. Ponomarev, L. M. Peter, A generalized theory of intensity modulated photocurrent spectroscopy (IMPS), Journal of Electroanallytical Chemistry, 1995, 396, 219-226.

[63] C. Y. Cummings, F. Marken, L. M. Peter, A. A. Tahir, K. G. U. Wijayantha, Kinetics and mechanism of lightdriven oxygen evolution at thin film $\alpha-\mathrm{Fe}_{2} \mathrm{O}_{3}$ electrodes, Chem. Commun., 2012, 48, 2027-2029.

[64] L. M. Peter, Energetics and kinetics of light-driven oxygen evolution at semiconductor electrodes: the example of hematite, J. Solid State Electrochem., 2013, 17, 315-326.

[65] H. K. Dunn, J. M. Feckl, A. Muller, D. Fattakhova-Rohlfing, S. G. Morehead, J. Roos, L. M. Peter, C. Scheu, T. Bein, Tin doping speeds up hole transfer during light-driven water oxidation at hematite photoanodes, Phys. Chem. Chem. Phys.,2014, 16, 24610-24620.

[66] J. E. Thorne, J. W. Jang, E. Y. Liu, D. W. Wang, Understanding the origin of photoelectrode performance enhancement by probing surface kinetics, Chem. Sci., 2016, 7, 3347-3354.

[67] D. Klotz, D. S. Ellis, H. Dotan, A. Rothschild, Empirical in operando analysis of the charge carrier dynamics in hematite photoanodes by PEIS, IMPS and IMVS, Phys. Chem. Chem. Phys., 2016, 18, 23438-23457.

[68] D. Klotz, D. A. Grave, H. Dotan, A. Rothschild, Empirical analysis of the photoelectrochemical impedance response of hematite photoanodes for water photo-oxidation, J. Phys. Chem. Lett. 2018, 9, 1466-1472.

[69] Y. Y. Avital, H. Dotan, D. Klotz, D. A. Grave, A. Tsyganok, B. Gupta, S. Kolusheva, I. Visoly-Fisher1, A. Rothschild, A. Yochelis, Two-site $\mathrm{H}_{2} \mathrm{O}_{2}$ photo-oxidation on haematite photoanodes, Nature Communications, 2018, 9,4060 .

[70] B. Klahr, T. Hamann, Water oxidation on hematite photoelectrodes: insight into the nature of surface states through in situ spectroelectrochemistry, J. Phys. Chem. C, 2014, 118, 10393-10399.

[71] T. Takashima, K. Ishikawa, H. Irie, Detection of Intermediate Species in Oxygen Evolution on Hematite Electrodes Using Spectroelectrochemical Measurements, J. Phys. Chem. C, 2016, 120, 24827-24834.

[72] O. Zandi, T. W. Hamann, Determination of photoelectrochemical water oxidation intermediates on haematite electrode surfaces using operando infrared spectroscopy, Nature Chem., 2016, 8, 778-783.

[73] J. P. Bigi, W. H. Harman, B. Lassalle-Kaiser, D. M. Robles, T. A. Stich, J. Yano, R. D. Britt, C. J. Chang, A highspin iron(IV)-oxo complex supported by a trigonal nonheme pyrrolide platform, J. Am. Chem. Soc. 2012, 134, 15361542 .

[74] A. R. McDonald, L. Que, High-valent nonheme iron-oxo complexes: synthesis, structure, and spectroscopy, Coord. Chem. Rev. 2013, 257, 414-428.

[75] H. Shi, J. A. Lercher, X. Y. Yu, Sailing into uncharted waters: recent advances in the in-situ monitoring of catalytic processes in aqueous environments, Catal. Sci. Technol. 2015, 5, 3035-3060.

[76] Y. C. Zhang, H. N. Zhang, A. N. Liu, C. C. Chen, W. J. Song, J. C. Zhao, Rate-limiting O-O bond formation pathways for water oxidation on hematite photoanode, J. Am. Chem. Soc., 2018, 140, 3264-3269.

[77] Z. X. Su, J. S. Baskin, W. Z. Zhou, J. M. Thomas, A. H. Zewail, Ultrafast elemental and oxidation-state mapping of hematite by 4D electron microscopy, J. Am. Chem. Soc., 2017, 139, 4916-4922.

[78] J. B. Sambur, T. Y. Chen, E. Choudhary, G. Q. Chen, E. J. Nissen, E. M. Thomas, N. M. Zou, P. Chen, Sub- 
particle reaction and photocurrent mapping to optimize catalyst-modified photoanodes, Nature, 2016, 530, 77-80. [79] B. Iandolo, A. Hellman, The role of surface states in the oxygen evolution reaction on hematite, Angew. Chem. Int. Ed. 2014, 53, 13404-13408.

[80] N. Yatom, O. Neufeld, M. C. Toroker, Toward settling the debate on the role of $\mathrm{Fe}_{2} \mathrm{O}_{3}$ surface states for water splitting, J. Phys. Chem. C, 2015, 119, 24789-24795.

[81] J. Noh, H. Li, O. I. Osman, S. G. Aziz, P. Winget, J. L. Brédas, Impact of hydroxylation and hydration on the reactivity of $\alpha-\mathrm{Fe}_{2} \mathrm{O}_{3}(0001)$ and (1-102) surfaces under environmental and electrochemical conditions, Adv. Energy Mater. 2018, 1800545.

[82] H. Li, M. S. Du, M. J. Mleczko, A. L. Koh, Y. Nishi, E. Pop, A. J. Bard, X. L. Zheng, Kinetic study of hydrogen evolution reaction over strained $\mathrm{MoS}_{2}$ with sulphur-vacancies using scanning electrochemical microscopy, $\mathrm{J}$. Am. Chem. Soc., 2016, 138, 5123-5129.

[83] J. Y. Kim, H. S. Ahn, A. J. Bard, Surface interrogation scanning electrochemical microscopy for a photoelectrochemical reaction-water oxidation on a hematite surface, Anal. Chem., 2018, 90, 3045-3049.

[84] M. R. Krumov, B. H. Simpson, M. J. Counihan, J. Rodriguez-Lopez, In situ quantification of surface intermediates and correlation to discharge products on hematite photoanodes using a combined scanning electrochemical microscopy approach, Anal. Chem., 2018, 90, 3050-3057.

[85] Y.C. Zhang, H.N. Zhang, H.W. Ji, W.H. Ma, C.C. Chen, J.C. Zhao, Pivotal role and regulation of proton transfer in water oxidation on hematite photoanodes, J. Am. Chem. Soc. 2016, 138, 2705-2711.

[86] S. Haschke, M. Mader, S. Schlicht, A. M. Roberts, A. M. Angeles-Boza, J. A.C. Barth, J. Bachmann, Direct oxygen isotope effect identifies the rate-determining step of electrocatalytic OER at an oxidic surface, Nature Communications, 2018, 9, 4565.

[87] R. Morrish, M. Rahman, J. M. Don MacElroy, C. A. Wolden, Activation of hematite nanorod arrays for photoelectrochemical water splitting, ChemSusChem, 2011, 4, 474-479.

[88] P. S. Shinde, A. Annamalai, J. H. Kim, S. H. Choi, J. S. Lee, J. S. Jang, Exploiting the dynamic Sn diffusion from deformation of FTO to boost the photocurrent performance of hematite photoanodes, Solar Energy Materials \& Solar Cells, 2015, 141, 71-79.

[89] A. Annamalai, A. Subramanian, U. Kang, H. Park, S. H. Choi, J. S. Jang, Activation of hematite photoanodes for solar water splitting: Effect of FTO deformation, J. Phys. Chem. C, 2015, 119, 3810-3817.

[90] O. Zandi, T. W. Hamann, Enhanced Water Splitting Efficiency Through selective surface state removal, J. Phys. Chem. Lett. 2014, 5, 1522-1526.

[91] P. S. Shinde, S. H. Choi, Y. Kim, J. Ryu, J. S. Jang, Onset potential behavior in a-Fe ${ }_{2} \mathrm{O}_{3}$ photoanodes: the influence of surface and diffusion Sn doping on the surface states, Phys. Chem. Chem. Phys., 2016, 18, 2495-2509.

[92] Y. Li, H. Chen, Facile fire treatment of nanostructured hematite with an enhanced photoelectrochemical water splitting performance, J. Mater. Chem. A, 2016, 4, 14974-14977.

[93] J. R. Xiao, H.L. Huang, Q.Y. Huang, L. Zhao, X. Li, X.L. Hou, H. Chen, Y.D. Li, Suppressing the electron-hole recombination rate in hematite photoanode with a rapid cooling treatment, Journal of Catalysis, 2017, 350, 48-55.

[94] M. Pyeon, T.P. Ruoko, J. Leduc, Y. Gönüllü, M. Deo, N. V. Tkachenko, S. Mathur, Critical role and modification of surface states in hematite films for enhancing oxygen evolution activity, J. Mater. Res., 2018, 33, 455-466.

[95] Y.C. Ling, G.M. Wang, J. Reddy, C.C. Wang, J.Z. Zhang, Y. Li, The influence of oxygen content on the thermal activation of hematite nanowires, Angew. Chem. Int. Ed. 2012, 51, 4074-4079.

[96] M. Forster, R. J. Potter, Y.C. Ling, Y. Yang, D. R. Klug, Y. Li, A.J. Cowan, Chem. Sci., 2015, 6, 4009-4016.

[97] Z.L. Wang, X. Mao, P. Chen, M. Xiao, S. A. Monny, S.C. Wang, M. Konarova, A.J. Du, L.Z. Wang, Understanding the roles of oxygen vacancies in hematite-based photoelectrochemical processes, Angew. Chem. 2019, $131,1042-1046$

[98] X. B. Chen, L. Liu, P. Y. Yu, S. S. Mao, Increasing solar absorption for photocatalysis with black hydrogenated titanium dioxide nanocrystals, Science, 2011, 331, 746-750.

[99] J. Moir, N. Soheilnia, K. Liao, P. O’Brien, Y. Tian, K. S. Burch, G. A. Ozin, Activation of ultrathin films of hematite for photoelectrochemical water splitting via $\mathrm{H}_{2}$ treatment, ChemSusChem, 2015, 8, 1557-1567.

[100] M. Li, J.J. Deng, A.W. Pu, P.P. Zhang, H. Zhang, J. Gao, Y.Y. Hao, J. Zhong, X.H. Sun, Hydrogen-treated hematite nanostructures with low onset potential for highly efficient solar water oxidation, J. Mater. Chem. A, 2014, 2, 6727-6733.

[101] Y. Yang, M. Forster, Y.C. Ling, G.M. Wang, T. Zhai, Y.X. Tong, A.J. Cowan, Y. Li, Acid treatment enables suppression of electron-hole recombination in hematite for photoelectrochemical water splitting, Angew. Chem. Int. Ed. 2016, 55, 3403-3407.

[102] X. L. Zhang, X. Wang, X. L. Yi, J. H. Ye, D. F. Wang, Alkali treatment for enhanced photoelectrochemical water oxidation on hematite photoanode, ACS Sustainable Chem. Eng. 2019, 7, 5420-5429.

[103] Q. N. Wu, D. D. Meng, Y. Zhang, Q. D. Zhao, Q. J. Bu, D. J. Wang, X. X. Zou, Y. H. Lin, S. Li, T. F. Xie, Acidtreated $\mathrm{Ti}^{4+}$ doped hematite photoanode for efficient solar water oxidationdInsight into surface states and charge separation, Journal of Alloys and Compounds, 2019, 782, 943-951.

[104] J. W. Jang, C. Du, Y. F. Ye, Y. J. Lin, X. H. Yao, J. Thorne, E. Liu, G. McMahon, J. F. Zhu, A. Javey, J. H. Guo, D. W. Wang, Enabling unassisted solar water splitting by iron oxide and silicon, Nature Communications, 2015, 6, 7447.

[105] G. Y. Liu, S. K. Karuturi, H. J. Chen, L. Spiccia, H. H, Tan, C. Jagadish, D. W. Wang, A. N. Simonov, A. Tricoli, Tuning the morphology and structure of disordered hematite photoanodes for improved water oxidation: A physical and chemical synergistic approach, Nano Energy, 2018, 53, 745-752.

[106] F. L. Formal, N. Tetreault, M. Cornuz, T. Moehl, M. Gratzel, K. Sivula, Passivating surface states on water splitting hematite photoanodes with alumina overlayers, Chem. Sci., 2011, 2, 737-743. 
[107] L. Steier, I. Herraiz-Cardona, S. Gimenez, F. Fabregat-Santiago, J. Bisquert, S. D. Tilley, M. Grätzel, Understanding the role of underlayers and overlayers in thin film hematite photoanodes, Adv. Funct. Mater. 2014, 24, 7681.

[108] A. Mettenbörger, Y. Gönüllü, T. Fischer, T. Heisig, A. Sasinska, C. Maccato, G. Carraro, C. Sada, D. Barreca, L. Mayrhofer, M. Moseler, A. Held, S. Mathur, Interfacial insight in multi-junction metal oxide photoanodes for water-

splitting applications, Nano Energy, 2016, 19, 415-427.

[109] P. Zhang, T. Wang, X. X. Chang, L. Zhang, J. L. Gong, Synergistic cocatalytic effect of carbon nanodots and $\mathrm{Co}_{3} \mathrm{O}_{4}$ nanoclusters for the photoelectrochemical water oxidation on hematite, Angew. Chem. Int. Ed. 2016, 55, 5851 -5855 .

[110] M. Forster, R. J. Potter, Y. Yang, Y. Li, A. J. Cowan, Stable $\mathrm{Ta}_{2} \mathrm{O}_{5}$ overlayers on hematite for enhanced photoelectrochemical water splitting efficiencies, ChemPhotoChem, 2018, 2, 183-189.

[111] H. J. Ahn, K. Y. Yoon, M. J. Kwak, J. Park, J. H. Jang, Boron doping of metal-doped hematite for reduced surface recombination in water splitting, ACS Catal. 2018, 8, 11932-11939.

[112] T. Hisatomi, F. L. Formal, M. Cornuz, J. Brillet, N. Tétreault, K. Sivula, M. Grätzel, Cathodic shift in onset potential of solar oxygen evolution on hematite by 13-group oxide overlayers, Energy Environ. Sci., 2011, 4, 25122515.

[113] Y. C. Ling, G.M. Wang, D. A. Wheeler, J. Z. Zhang, Y. Li, Sn-doped hematite nanostructures for photoelectrochemical water splitting, Nano Lett. 2011, 11, 2119-2125.

[114] M. A. Mahadik, A. Subramanian, J.H. Ryu, M. Cho, J.S. Jang, A hydrothermally grown CdS nanograinsensitized 1D Zr: $\alpha-\mathrm{Fe}_{2} \mathrm{O}_{3} / \mathrm{FTO}$ photoanode for efficient solar-light-driven photoelectrochemical performance, Dalton Trans., 2017, 46, 2377-2386.

[115] M.Y. Li, Y. Yang, Y. C. Ling, W. T. Qiu, F. X. Wang, T. Y. Liu, Y. Song, X. X. Liu, P. P. Fang, Y. X. Tong, Y. Li, Morphology and doping engineering of Sn-doped hematite nanowire photoanodes, Nano Lett. 2017, 17, 2490-2495.

[116] C. Lohaus, A. Klein, W. Jaegermann, Limitation of fermi level shifts by polaron defect states in hematite photoelectrodes, Nature Communications, 2018, 9, 4309.

[117] D. Monllor-Satoca, M. Bartsch, C. Fabrega, A. Genç, S. Reinhard, T. Andreu, J. Arbiol, M. Niederberger, J. R. Morante, What do you do, titanium? Insight into the role of titanium oxide as a water oxidation promoter in hematitebased photoanodes, Energy Environ. Sci., 2015, 8, 3242-3254.

[118] Z. L. Wang, F.T. Fan, S. Y. Wang, C. M. Ding, Y. L. Zhao, C. Li, Bridging surface states and current-potential response over hematite-based photoelectrochemical water oxidation, RSC Adv., 2016, 6, 85582-85586.

[119] P. S. Bassi, R. P. Antony, P. P. Boix, Y. N. Fang, J. Barber, L. H. Wong, Crystalline $\mathrm{Fe}_{2} \mathrm{O}_{3} / \mathrm{Fe}_{2} \mathrm{TiO}_{5}$ heterojunction nanorods with efficient charge separation and hole injection as photoanode for solar water oxidation, Nano Energy, 2016, 22, 310-318.

[120] O. Zandi, B. M. Klahr, T. W. Hamann, Highly photoactive Ti-doped a-Fe $\mathrm{O}_{3}$ thin film electrodes: resurrection of the dead layer, Energy Environ. Sci., 2013, 6, 634-642.

[121] F. Li, J. Li, J. Zhang, L. L. Gao, X. F. Long, Y. P. Hu, S. W. Li, J. Jin, J. T. Ma, NiO nanoparticles anchored on phosphorus-doped a- $\mathrm{Fe}_{2} \mathrm{O}_{3}$ nanoarrays: An efficient hole extraction $\mathrm{p}$-n heterojunction photoanode for water oxidation, ChemSusChem, 2018, 11, 2156-2164.

[122] L. P. Gong, J. L. Xie, X. R. Liang, J. Y. Xiong, S. L. Yi, X. Y. Zhang, C. M. Li, Tailoring surface states by sequential doping of $\mathrm{Ti}$ and $\mathrm{Mg}$ for kinetically enhanced hematite photoanode, Journal of Colloid and Interface Science, 2019, 542, 441-450.

[123] J. W. Park, M. A. Mahadik, H. Q. Ma, G. W. An, H. H. Lee, S. H. Choi, W. S. Chae, H. S. Chung, J. S. Jang, Improved interfacial charge transfer dynamics and onset shift in nanostructured hematite photoanodes via efficient $\mathrm{Ti}^{4+} / \mathrm{Sn}^{4+}$ heterogeneous self-doping through controlled $\mathrm{TiO}_{2}$ underlayers, ACS Sustainable Chem. Eng. 2019, 7, 6947-6958.

[124] M. A. Mahadik, A. Subramanian, H. S. Chung, M. Cho, J. S. Jang, CdS/Zr: $\mathrm{Fe}_{2} \mathrm{O}_{3}$ nanorod arrays with $\mathrm{Al}_{2} \mathrm{O}_{3}$ passivation layer for photoelectrochemical solar hydrogen generation, ChemSusChem, 2017, 10, 2030-2039.

[125] F. Li, J. Li, L. L. Gao, Y. P. Hu, X. F. Long, S. Q. Wei, C. L. Wang, J. Jin, J. T. Ma, Construction of an efficient hole migration pathway on hematite for efficient photoelectrochemical water oxidation, J. Mater. Chem. A, 2018, 6, $23478-23485$.

[126] S. Chen, J. H. Li, J. Bai, L. G. Xia, Y. Zhang, L. S. Li, Q. J. Xu, B. X. Zhou, Electron blocking and hole extraction by a dual-function layer for hematite with enhanced photoelectrocatalytic performance, Applied Catalysis B: Environmental, 2018, 237, 175-184.

[127] A. G. Tamirat, A. A. Dubale, W. N. Su, H. M. Chen, B. J. Hwang, Sequentially surface modified hematite enables lower applied bias photoelectrochemical water splitting, Phys. Chem. Chem. Phys., 2017, 19, 20881-20890.

[128] A. Y. Ahmed, M. G. Ahmed, T. A. Kandiel, Hematite photoanodes with size-controlled nanoparticles for enhanced photoelectrochemical water oxidation, Applied Catalysis B: Environmental, 2018, 236, 117-124.

[129] J. W. Moir, E. V. Sackville, U. Hintermair, G. A. Ozin, Kinetics versus charge separation: Improving the activity of stoichiometric and non-stoichiometric hematite photoanodes using a molecular iridium water oxidation catalyst, J. Phys. Chem. C, 2016, 120, 12999-13012.

[130] S. C. Riha, B. M. Klahr, E. C. Tyo, S. Seifert, S. Vajda, M. J. Pellin, T. W. Hamann, A. B. F. Martinson, Atomic layer deposition of a submonolayer catalyst for the enhanced photoelectrochemical performance of water oxidation with hematite, ACS Nano, 2013, 7, 2396-2405.

[131] B. Klahr, S. Gimenez, F. Fabregat-Santiago, J. Bisquert, T. W. Hamann, Photoelectrochemical and impedance spectroscopic investigation of water oxidation with "Co-Pi"-coated hematite electrodes, J. Am. Chem. Soc. 2012, 134, 16693-16700. 
[132] G. M. Carroll, D. R. Gamelin, Kinetic analysis of photoelectrochemical water oxidation by mesostructured Co$\mathrm{Pi} / \mathrm{a}-\mathrm{Fe}_{2} \mathrm{O}_{3}$ photoanodes, J. Mater. Chem. A, 2016, 4, 2986-2994.

[133] W. Li, S. W. Sheehan, D. He, Y. M. He, X. H. Yao, R. L. Grimm, G. W. Brudvig, D. W. Wang, Hematite-based solar water splitting in acidic solutions: Functionalization by mono- and multilayers of iridium oxygen-evolution catalysts, Angew. Chem. 2015, 127, 11590-11594.

[134] W. Li, D. He, S. W. Sheehan,Y. M. He, J. E. Thorne, X. H. Yao, G. W. Brudvig, D. W. Wang, Comparison of heterogenized molecular and heterogeneous oxide catalysts for photoelectrochemical water oxidation, Energy Environ. Sci., 2016, 9, 1794-1802.

[135] Y. Y. Zhao, K. R. Yang, Z. C. Wang, X.X. Yan, S. F. Cao, Y. F. Ye, Q. Dong, X. Z. Zhang, J. E. Thorne, L. Jin, K. L. Materna, A. Trimpalis, H. Y. Bai, S. C. Fakra, X. Y. Zhong, P. Wang, X. Q. Pan, J. H. Guo, M. FlytzaniStephanopoulos, G. W. Brudvig, V. S. Batista, D. W. Wang, Stable iridium dinuclear heterogeneous catalysts supported on metal-oxide substrate for solar water oxidation, PNAS, 2018, 115, 2902-2907.

[136] C.H. Cui, M. Heggen, W. D. Zabka, W. Cui, J. Osterwalder, B. Probst, R. Alberto, Atomically dispersed hybrid nickel-iridium sites for photoelectrocatalysis, Nature Communications, 2017, 8, 1341.

[137] J. F. Zhang, R. Garcia-Rodriguez, P. Cameron, S. Eslava, Role of cobalt-iron (oxy)hydroxide $\left(\mathrm{CoFeO}_{\mathrm{x}}\right)$ as oxygen evolution catalyst on hematite photoanodes, Energy Environ. Sci., 2018, 11, 2972-2984.

[138] D. K. Zhong, M. Cornuz, K. Sivula, M. Gratzel, D. R. Gamelin, Photo-assisted electrodeposition of cobaltphosphate (Co-Pi) catalyst on hematite photoanodes for solar water oxidation, Energy Environ. Sci., 2011, 4, 17591764.

[139] J. Y. Kim, D. H. Youn, K. Kang, J. S. Lee, Highly conformal deposition of an ultrathin FeOOH layer on a hematite nanostructure for efficient solar water splitting, Angew. Chem. Int. Ed. 2016, 55, 10854-10858.

[140] I. S. Cho, H. S. Han, M. Logar, J. Park, X. L. Zheng, Enhancing low-bias performance of hematite photoanodes for solar water splitting by simultaneous reduction of bulk, interface, and surface recombination pathways, $A d v$. Energy Mater. 2016, 6, 1501840.

[141] P.Y. Tang, L.J. Han, F. S. Hegner, P. Paciok, M. Biset-Peiró, H.C. Du, X.K. Wei, L. Jin, H.B. Xie, Q. Shi, T. Andreu, M. Lira-Cantú, M. Heggen, R. E Dunin-Borkowski, N. López, J. R. Galán-Mascarós, J. R. Morante, J. Arbiol, Boosting Photoelectrochemical Water Oxidation of Hematite by Surface States Modification, Available at SSRN: http://dx.doi.org/10.2139/ssrn.3327226.

[142] H. Zhu, M. M. Zhao, J. K. Zhou, W. C. Lia, H. Y. Wang, Z. Xu, L. Lu, L. Pei, Z. Shi, S. C. Yan, Z. S. Li, Z. G. Zou, Surface states as electron transfer pathway enhanced charge separation in $\mathrm{TiO}_{2}$ nanotube water splitting photoanodes, Applied Catalysis B: Environmental, 2018, 234, 100-108.

[143] M. Antuch, P. Millet, A. Iwase, A. Kudo, The role of surface states during photocurrent switching: Intensity modulated photocurrent spectroscopy analysis of $\mathrm{BiVO}_{4}$ photoelectrodes, Applied Catalysis B: Environmental, 2018, 237, 401-408.

[144] M. R. Nellist, F. A. L. Laskowski, J. J. Qiu, H. Hajibabaei, K. Sivula, T. W. Hamann, S. W. Boettcher, Potentialsensing electrochemical atomic force microscopy for in operando analysis of water-splitting catalysts and interfaces, Nature Energy, 2018, 3, 46-52.

[145] N. Zou, X. Zhou, G. Chen, N. M. Andoy, W. Jung, G. Liu, P. Chen, Cooperative communication within and between single nanocatalysts, Nature Chem. 2018, 10, 607-614.

[146] B. H. Han, K. A. Stoerzinger, V. Tileli, A. D. Gamalski, E. A. Stach, Y. Shao-Horn, Nanoscale structural oscillations in perovskite oxides induced by oxygen evolution, Nature Materials, 2017, 16, 121-126.

[147] R. T. Chen, S. Pang, H.Y. An, J. Zhu, S. Ye, Y.Y. Gao, F.T. Fan, C. Li, Charge separation via asymmetric illumination in photocatalytic $\mathrm{Cu}_{2} \mathrm{O}$ particles, Nature Energy, 2018, 3, 655-663.

[148] J. Knöppel, S. Y. Zhang, F. D. Speck, K. J. J. Mayrhofer, C. Scheu, S. Cherevko, Time-resolved analysis of dissolution phenomena in photoelectrochemistry-A case study of $\mathrm{WO}_{3}$ photocorrosion, Electrochemistry Communications, 2018, 96, 53-56.

[149] J.J. Qiu, H. Hajibabaei, M. R. Nellist, F. A. L. Laskowski, T. W. Hamann, S. W. Boettcher, Direct in Situ measurement of charge transfer processes during photoelectrochemical water oxidation on catalyzed hematite, $A C S$ Cent. Sci. 2017, 3, 1015-1025.

[150] J.J Qiu, H. Hajibabaei, M. R. Nellist, F. A. L. Laskowski, S. Z. Oener, T. W. Hamann, S. W. Boettcher, Catalyst deposition on photoanodes: The roles of intrinsic catalytic activity, catalyst electrical conductivity, and semiconductor Morphology, ACS Energy Lett. 2018, 3, 961-969.

[151] F. A. L. Laskowski, M. R. Nellist, J. J. Qiu, S. W. Boettcher, Metal oxide/(oxy)hydroxide overlayers as hole collectors and oxygen-evolution catalysts on water-splitting photoanodes, J. Am. Chem. Soc. 2019, 141, 1394-1405. 